\title{
Predicting jack-up spudcan installation in sand overlying stiff clay
}

\section{Pan Hu}

Research Associate

Centre for Offshore Foundation Systems and ARC Centre of Excellence for Geotechnical Science and Engineering,

The University of Western Australia, 35 Stirling Highway, Crawley, WA6009, Australia Email:pan.hu@uwa.edu.au

\section{Mark Jason Cassidy}

ARC Laureate Fellow and Lloyd's Register Foundation Chair of Offshore Foundations Centre for Offshore Foundation Systems and ARC Centre of Excellence for Geotechnical Science and Engineering,

The University of Western Australia, 35 Stirling Highway, Crawley, WA6009, Australia Email: mark.cassidy@uwa.edu.au

- Number of words: 4619 (text only)

- Number of tables: 4

- Number of figures: 15 


\begin{abstract}
There has been a constant trend towards larger mobile jack-ups capable of operating for extended periods in deeper water and in harsher environmental conditions. This is increasing both the size of their spudcan footings and the operational bearing pressures. Though some new analytical methods to predict the load-penetration profile have been proposed, and shown to fit centrifuge experiments well, these methods were calibrated mainly using experimental and numerical data for sand overlying soft clay. This paper reports six centrifuge tests simulating spudcan installation in sand overlying a stiff clay. These are complemented with large-deformation finite element analyses, simulating the continuous penetration of the spudcan in sand over stiff clay. Modified Mohr-Coulomb and Tresca models were used to describe the sand and clay behaviour, accounting for the effects of strain softening on the response of the soil. These results provide confidence that a recently published analytical method to predict the peak capacity can indeed be extended to high bearing resistances and stronger underlying clays. Bearing capacity factors used to predict capacity in the underlying clay have, however, been updated to reflect the new database of results. A new formulae that explicitly accounts for increasing strength with depth profiles is provided.
\end{abstract}

\title{
Keywords:
}

centrifuge modelling; spudcan; sand; clay; bearing capacity; punch-through 


\section{Introduction}

In water up to a depth of approximately $150 \mathrm{~m}$, mobile independent leg jack-up rigs are widely used to perform most offshore drilling. The jack-up units are designed for more onerous conditions leading to increased spudcan bearing pressures. Although the popular rig classes exhibited maximum vertical installation bearing pressure in the range of 200 to 600 $\mathrm{kPa}$, some of the reported field cases have indicated higher bearing pressures (see Fig. 1). Are the calculation methods used to predict the vertical installation of spudcans appropriate for these pressures and all offshore conditions?

For instance, the punch-through of a spudcan through a layer of sand into underlying clay has been intensively investigated in a geotechnical centrifuge by Craig and Chua (1990), Teh (2007), Lee (2009), Teh et al. (2010), Lee et al. (2013a), Hossain et al. (2016) and Hu et al. (2014a, 2016). Table 1 summarises the testing database, with the shear strength of the clay at the sand-clay interface $s_{\text {um }}$ ranging from 7.2 to $25.8 \mathrm{kPa}$ and the shear strength gradient in the range of $0-2.1 \mathrm{kPa} / \mathrm{m}$. Because it is easier to lay in a centrifuge this database consists of soft clays. However, for many of the punch-through locations of greatest concern, such as in the South Baltic and the North Sea, layered sand over stiff clay stratigraphy with $s_{\mathrm{u}}>40 \mathrm{kPa}$ are common (Werno et al. 1987; Kellezi et al. 2005; Kellezi and Stadsgaard 2012). There is a need to confirm the applicability of analytical methods in these stronger soil profiles. It is noted that the term "stiff clay" is used somewhat generically in this paper to describe clays of strength greater than those previously used in the centrifuge testing and numerical analysis on the sand-over-clay problem. These are clays greater than $40 \mathrm{kPa}$, though this is slightly different to that defined in ISO (2012).

Load spread and punching shear are the 'standard' methods included to estimate the peak spudcan bearing pressure in sand overlying clay in the ISO 19905-1 guidelines (ISO 2012). There is mounting evidence that these methods produce low estimates of the spudcan bearing 
pressure during punch-through failure when the undrained shear strength of the clay is low (Teh et al. 2010; Lee et al. 2013a; Hu et al. 2015b). However, whether such underestimation of the spudcan bearing pressure also occurs for the higher underlying undrained shear strengths often encountered offshore requires further validation.

Recently, a new analytical penetration resistance-depth profile prediction method (hereinafter called the $\mathrm{Hu}$ et al. method) was proposed (Lee et al. 2013b; Hu et al. 2014b, 2015a). It was calibrated using a testing and numerical database with soft clay strength of $10-40 \mathrm{kPa}$ at the sand-clay interface and strength gradient of $1.5-2.5 \mathrm{kPa} / \mathrm{m}$ (Lee et al. 2013a; Hu et al. 2014a, 2015a, 2016). In the prediction of the peak penetration resistance in the upper sand layer, the stress level and dilatant response, as well as the embedment depth, are taken into account using a discretised silo approach. In the prediction of spudcan capacity in the underlying clay, both the thickness of the trapped sand beneath the spudcan and the clay's undrained shear strength increment with depth are accounted for.

The motivation for this paper emanates from the need to characterise spudcan installation in sand over stiff clay and to validate analytical methods used to calculate load-penetration profiles. The term "stiff clay" is used for the clays with strength greater than $40 \mathrm{kPa}$ in the following analyses. The main objectives of the testing and numerical programme are: (a) to model experimentally the penetration resistance of a spudcan of generalised geometry penetrating medium-dense sand overlying stiff clay in a beam centrifuge and to extend the existing testing database to incorporate clay of higher undrained shear strength; (b) to evaluate the performance of the guideline methods in estimating the spudcan penetration resistance in sand over stiff clay soils; and (c) to validate the $\mathrm{Hu}$ et al. method to predict spudcan penetration resistance-depth profiles. This will provide confidence for use of these methods in typical offshore conditions faced by practitioners. 


\section{Testing programme}

Physical modelling of spudcan penetration in medium-dense sand overlying stiff clay was conducted using the beam centrifuge at the University of Western Australia (UWA). The centrifuge has a swinging platform with a standard rectangular strongbox. It has internal dimensions of $650 \mathrm{~mm}$ (length) $\times 390 \mathrm{~mm}$ (width) $\times 325 \mathrm{~mm}$ (depth), representing a prototype testing area of $130 \mathrm{~m} \times 78 \mathrm{~m} \times 65 \mathrm{~m}$ respectively when testing at $200 \mathrm{~g}$. Tests were performed using four model spudcans of the same shape, but with dimensions scaled according to Fig. 2. The diameter of the model spudcan, $D$, ranged from $30 \mathrm{~mm}$ to $60 \mathrm{~mm}$. The models were made from duraluminium and included a $13^{\circ}$ shallow conical underside profile (included angle of $154^{\circ}$ ) and a $76^{\circ}$ protruding spigot. These spudcans were the same shape as those used in the tests of sand overlying soft clay by Teh et al. (2010), Lee et al. (2013a) and Hu et al. (2014a) and in previous combined loading experiments of Martin and Houlsby (2000), Cassidy et al. (2004) and Vlahos et al. (2011).

\subsection{Sample preparation}

Commercially available super-fine silica sand and kaolin clay were adopted in all the centrifuge tests to form the sand and clay layers, respectively. Both materials have been well characterised and used extensively in the geotechnical centrifuges at UWA. The key properties of the sand and clay are summarised in Table 2 .

Initially, sand was laid at the base of a strongbox in a layer $\sim 10 \mathrm{~mm}$ thick and saturated to form a drainage layer. The kaolin clay was mixed with water under vacuum to form a clay slurry to about two times the liquid limit of clay. The kaolin clay slurry was then transferred into the strongbox and consolidated overnight. Seven specially designed steel beams $(50 \mathrm{~mm}$ $\times 50 \mathrm{~mm}$ cross-section) were placed along the curvature of the strongbox to surcharge the clay. A brass mesh together with a geo-fabricwere used as a flexible barrier between the 
kaolin clay and the overburden, which was strong enough to support the steel beams but flexible and porous so as not to point load the sample or alter the pore-pressure dissipation (see Fig. 3). The underlying clay was then over-consolidated at an acceleration of $300 \mathrm{~g}$ until no further displacement of the clay was recorded, indicating the clay was fully consolidated. All tests were conducted at $200 \mathrm{~g}$, and the over-consolidation ratio, OCR, for the underlying clay was at least 1.5. After consolidation, the clay was scraped to form a smooth surface. The top sand layer was formed by pluviating fine sand particles. The sand drop height, hopper travel speed and opening were controlled to create medium-dense sand. The soil sample was then saturated and subjected to an acceleration of $200 \mathrm{~g}$, with the effective centrifuge radius being set at two-thirds from the bottom of the clay. The clay thickness was measured to be $193 \mathrm{~mm}$, with a sample thickness of $213 \mathrm{~mm}$ and $223 \mathrm{~mm}$, depending on the thickness of the top sand.

\subsection{Testing procedure}

A total of six spudcan penetration tests were performed in medium-dense sand overlying stiff clay with sand thickness $H_{\mathrm{s}}$ of 20 and $30 \mathrm{~mm}$, for which the ratio $H_{\mathrm{s}} / D$ was between 0.33 and 1.0. All the tests were spaced at least $1.5 D$ edge-to-edge and with a clear minimum $1.5 D$ between the spudcan edge and the sidewall of the strongbox. A free layer of water was maintained above the sample being tested. As detailed in Table 3, three tests of varying spudcan diameter were performed with the initial sand thickness of $30 \mathrm{~mm}$. Following these tests the sand was further scraped back to $20 \mathrm{~mm}$, allowing three tests to be performed at different $H_{\mathrm{s}} / D$ ratios. The bottom clay was re-consolidated at $200 \mathrm{~g}$ overnight after the scraping process.

The installation of each spudcan was carried out in-flight at a constant penetration rate until the spudcan reached the target depth of $2 D \sim 3 D$. The penetration rates were determined such that drained behaviour in sand and undrained behaviour in clay were both attained. The 
normalised penetration rate, $V\left(=v D / c_{\mathrm{v}}\right)$, has been widely used to describe the drainage condition (Finnie and Randolph, 1994; Chung et al. 2006; Cassidy, 2012), where $v$ is the penetration rate of the spudcan, and $c_{\mathrm{v}}$ is the consolidation coefficient. Consistent with previous tests by Lee et al. (2013a) and $\mathrm{Hu}$ et al. (2014a), the normalised penetration rate $V$ was maintained as 120 for all the tests by varying the penetration rate accordingly. Thus, the penetration rates for spudcans with $D=30 \mathrm{~mm}$ and $70 \mathrm{~mm}$ ranged from $0.254 \mathrm{~mm} / \mathrm{s}$ to $0.109 \mathrm{~mm} / \mathrm{s}$, respectively.

\subsection{Soil characterisation}

The relative density, $I_{\mathrm{D}}$, of the sand was determined by extracting three samples in the strongbox using $60 \mathrm{~mm}$ diameter sampling tubes (at 1g). The samples were collected carefully from the bed ensuring minimal disturbance, and yielded an average relative density of $65 \%$, with a standard deviation of $1.6 \%$, indicating relatively uniform medium-dense sand. The submerged unit weight of the sand, $\gamma^{\prime}$ s, was measured to be $10.4 \mathrm{kN} / \mathrm{m}^{3}$. The submerged unit weight of the clay, $\gamma_{c}^{\prime}$, was $7.8 \mathrm{kN} / \mathrm{m}^{3}$ on average, which was obtained by measuring the $20 \mathrm{~mm}$ diameter samples extracted by a tube sampler.

Characterisation tests on clay were carried out in-flight using a T-bar penetrometer with a diameter of $5 \mathrm{~mm}$ and a length of $20 \mathrm{~mm}$ (see insert in Fig. 4). T-bar penetrometer tests were performed after inserting a sample tube through the sand layer to the clay surface, digging out the sand particles inside the tube and cleaning the spot using a vacuum cleaner. This was intended to eliminate the influence of entrapped sand beneath the penetrometer and to avoid potential damage to the penetrometer that may have occurred if it penetrated the sand layer. The T-bar was penetrated and extracted at a velocity of $1.522 \mathrm{~mm} / \mathrm{s}$, chosen to balance the rate effects against ensuring undrained behaviour in the clay. An intermediate roughness Tbar factor of 10.5 was assumed, with the derived profiles for two T-bar tests provided in Fig. 
4. The sand-clay interface shear strength, $s_{\text {um, }}$ and shear strength gradient, $k$, for the underlying clay are summarised in Table 3.

In addition to the standard T-bar tests, three cyclic penetration and extraction tests were undertaken to provide an assessment of the fully remoulded strength and hence the sensitivity of the soil. These cyclic remoulding tests were conducted at a sample depth of $125 \mathrm{~mm}$ and involved cycling the T-bar by $\pm 25 \mathrm{~mm}$ (i.e., \pm 5 T-bar diameters) over 11 cycles. The results from the cyclic T-bar tests provide insight into the degradation of the soil, as plotted against the number of cycles in Fig. 5. The degradation factor is defined as the resistance (penetration/extraction) encountered by the T-bar at the middle depth of the cycles normalised by the initial penetration resistance (taken as cycle 0.5, Randolph 2004). Good repeatability in the sample was found, and the limiting degradation factor was calculated as 0.4 , indicating a sensitivity $\left(S_{\mathrm{t}}\right)$ of $1 / 0.4=2.5$. This is consistent with other cyclic T-bar tests performed on UWA kaolin clay (e.g., Hodder et al. 2010; Mana et al. 2012).

\section{Testing results and predictions}

The testing and numerical results are presented using prototype scale. The spudcan penetration resistance profiles for 6 medium dense sand overlying stiff clay centrifuge tests are shown in Figs. 6-7. They are grouped for two thicknesses of the sand layer. The displacements are measured (zeroed) from the position of the bottom shoulder of the spudcan embedded at the soil surface (RP in Fig. 2b). The $q_{\text {peak }}$ values are measured from the testing profiles in Figs. 6-7. In general, all the testing profiles indicate a potential risk for rapid vertical displacement of the spudcan.

\subsection{Prediction of peak penetration resistance}


The experimental conditions were used to retrospectively predict the peak penetration resistance using the ISO (2012) guidelines and the method of $\mathrm{Hu}$ et al.

Average $s_{\mathrm{u}}$ over $D / 2$ depth below the clay surface is adopted for the guideline methods. The peak resistances predicted by the load spread method with a load spread ratio $n_{\mathrm{s}}$ of 3 and 5 and the punching shear method in ISO (2012) are plotted against the experimentally measured values in Fig. 8. For both methods, low predictions of $q_{\text {peak }}$ are obtained, with the predicted peak penetration resistances falling within $20-50 \%$ of the measured peak penetration resistances.

In contrast to the ISO (2012) recommendations, a good fit between the testing and predicted peak penetration resistance from the model in the Hu et al. method is shown in Fig. 8, with an average difference of only $0.79 \%$ and a coefficient of variation $(\mathrm{COV})$ of $2.9 \%$. In the analytical model, the $q_{\text {peak }}$ is the sum of the frictional resistance in the sand, the bearing capacity of the underlying clay, and the weight of the sand frustrum. The frictional resistance in the sand and the weight of the sand frustrum are the main components of $q_{\text {peak }}$ (on average accounting for $67.3 \%$ of $q_{\text {peak }}$ in the testing database), while the expression for the bearing capacity of the underlying clay incorporates the effect of the various clay strengths. Therefore, although the analytical model is calibrated on $s_{\mathrm{um}}$ of $7.2-25.8 \mathrm{kPa}$ and footing pressures of between $154.8-699.5 \mathrm{kPa}$, comparisons of the predictions indicate that it is capable of predicting the peak penetration resistance when the clay strengths increase to $43.9 \mathrm{kPa}$. It is also more accurate than the ISO methods. No modification to the peak prediction method of $\mathrm{Hu}$ et al. seems necessary.

\subsection{Prediction of bearing capacity in the underlying clay}


The full profiles of penetration resistance against depth were predicted using the $\mathrm{Hu}$ et al. method for all six centrifuge tests, as shown in Fig. 9. The large deformation finite element simulations are also plotted in this figure, but will not be discussed until the next section.

The Hu et al. method, in general, captures the trend of the testing profiles. As discussed in the above section, the $q_{\text {peak }}$ was well predicted by the Hu et al. method. For tests SP4-SP6, the penetration resistances in the underlying clay are estimated reasonably well, however, there is an over-prediction for stiff clay tests SP1-SP3 (tests where the shear strengths of the underlying clay are beyond the range for which the $\mathrm{Hu}$ et al. method was calibrated). The reason might be the bearing capacity factor is expressed as a linear relation with $H_{\mathrm{s}} / D$ with the effect of $\mathrm{kD} / \mathrm{s}_{\mathrm{um}}$ gradients uncalibrated. To supplement the experimental evidence just described, numerical simulations on more cases of sand over stiff clay are required to further validate the performance of the $\mathrm{Hu}$ et al. method.

\section{Large deformation finite element analyses}

\subsection{Analysis details and soil models}

Apart from the testing data reported in this investigation, three-dimensional LDFE analyses were undertaken to simulate the continuous penetration of spudcans from the seabed, supplementing the testing database to a larger range of underlying stiff clay shear strength. The LDFE analyses were performed using the Coupled Eulerian-Lagrangian (CEL) approach in the commercial FE package Abaqus/Explicit. This large-deformation analysis approach provides a full spudcan penetration resistance profile and reveals the evolving soil flow patterns. The CEL approach has been employed to simulate spudcan penetration in singleand two-layer clays (Tho et al. 2012) and spudcan penetration in sand overlying clay (Qiu and Henke 2011; Qiu and Grabe 2012; Hu et al. 2014b; 2015a). The spudcan and soils were

discretised using Lagrangian and Eulerian meshes, respectively. Throughout the analysis, the 
soil mesh remained unchanged, and the soil materials were allowed to flow in or out of the Eulerian element. A fine mesh zone with horizontal extension of $0.75 D$ was set to cover significant soil movements by the spudcan penetration, while a coarse mesh zone with horizontal extension of $2.5 \mathrm{D}$ was adopted to minimise the boundary effects. Through contact between the spudcan and soil materials, the penetration resistance was obtained. The frictional spudcan-sand contact was described by the Coulomb friction law, with the coefficient of friction equal to $\alpha \tan \varphi_{\mathrm{cv}}$, where $\alpha$ is the spudcan roughness factor, and $\varphi_{\mathrm{cv}}$ is the

critical state friction angle of sand. The spudcan was penetrated with a constant velocity of $0.2 \mathrm{~m} / \mathrm{s}$, minimising the inertia effect while maintaining numerical accuracy. Only a quarter of the domain was modelled to reduce the computational cost by taking advantage of the axial symmetry of the problem. An element size of $0.025 \mathrm{D}$ close to the spudcan was selected to balance computational accuracy and efficiency.

The sand was modelled using the modified Mohr-Coulomb model, updating the friction angle and dilation angle to consider the softening effect (following $\mathrm{Hu}$ et al. 2015a). The post-peak response of the sand was effectively captured in a computationally practical manner by incorporating this model in the simulation. The underlying clay was modelled as a linear elastic-perfectly plastic material obeying a Tresca yield criterion, which was extended to take the effect of progressive softening into account. The elastic parameters for clay were considered to be independent of failure stresses, so a constant value throughout the penetration process was used. A uniform stiffness ratio $E / s_{\mathrm{u}}=500$ was taken throughout the clay profile. Poisson's ratio was 0.49 to approximate constant-volume shearing under undrained conditions. More detailed discussions of the adopted constitutive models are given in $\mathrm{Hu}$ et al. (2015a).

\subsection{Retrospective simulation of centrifuge tests}


The penetration resistance-depth profiles of six centrifuge tests were retrospectively simulated using the CEL approach. As shown in Fig. 9, the CEL approach in general captures the trend of the testing profiles, though under-estimation in $q_{\text {peak }}$ is observed and is more pronounced in thicker-sand-layer cases. One possible reason of the under-estimation (especially for very dense or thick sand) might be the friction and dilation angles calculated using Bolton's equation for the CEL analyses are lower than that corresponding to the low mean stress along the sand failure surface at $q_{\text {peak. }}$ For all the centrifuge testing profiles, the CEL approach predicts the profiles in the underlying clay reasonably well, indicating the reliability of using this approach for parametric studies in sand over stiff clay soils.

\subsection{Parametric studies}

In addition to the retrospective simulations of the six centrifuge experiments, a complementary set of parametric analyses was performed to quantify the influences of several critical factors, i.e., $H_{\mathrm{s}} / D, s_{\mathrm{um}}$ and $k$. The details of spudcan geometries and soil properties simulated are listed in Table 4. The normalised sand thickness $H_{\mathrm{s}} / D$ was varied from 0.1 to 1.0 ; the clay strength at the sand-clay interface $s_{\mathrm{um}}$ from 50 to $100 \mathrm{kPa}$; and the shear strength gradient $k$ from 0 to $5 \mathrm{kPa} / \mathrm{m}$.

An example of the deformed soil layers and contours of the shear strength of the clay after a spudcan penetration (case PS12) is shown in Fig. 10. A sand plug is clearly trapped underneath the spudcan, mobilising higher bearing capacity of the soil compared with the single clay case. The measurements from these numerical analyses indicate the height of the sand plug is $\sim 0.9 H_{\mathrm{s}}$, consistent with the conclusion in Teh (2007) and $\mathrm{Hu}$ et al. (2016). This manifests that the height of the sand plug was not diminished by interaction with the stiffer underlying clay. Also shown in Fig. 10 is that the sand in the upper layer partially flowed back to the top of the spudcan, hindering the plastic flow around the spudcan edge, and a 
cavity was formed close to the sand surface. The soil adjacent to the spudcan edge flowed outwards and upwards, resulting in heave at the soil surface. It can also be observed that the disturbed underlying clay was $\sim 1.5 D$ from the edge of the spudcan, validating that the chosen distance between each testing site is safe from any disturbance.

The effects of clay shear strength at the sand-clay interface, $s_{\mathrm{um}}$, and strength gradient, $k$, on the penetration resistance are demonstrated in Fig. 11(a), for the example case of a normalised sand thickness of $H_{\mathrm{s}} / D=0.7$. The depths of peak penetration resistance are similar for the three cases and they all show similar trend in penetration resistance after $q_{\text {peak. }}$. For $k=2 \mathrm{kPa} / \mathrm{m}$, when $s_{\text {um }}$ is increased from $50 \mathrm{kPa}$ to $90 \mathrm{kPa}$, the increase in the penetration resistance is approximately the same (a factor of $\sim 1.4$ ) for the overall penetration depth. This indicates that the shear strength of clay contributes the same proportion to both the peak penetration resistance in the top sand layer and the penetration resistance in the underlying clay layer. This trend also indicates that a constant bearing capacity factor, $N_{\mathrm{c}}$, should be used for a constant ratio of $H_{\mathrm{s}} / D$ and $k D / s_{\mathrm{um}}$.

As shown in Fig. 11(b), the normalised sand thickness $H_{\mathrm{s}} / D$ has an obvious effect on the penetration resistance. A severe punch-through potential is observed at $H_{\mathrm{s}} / D=0.9$, with a sharp reduction in penetration resistance after $q_{\text {peak }}$ during the vertical penetration. In the case of $H_{\mathrm{s}} / D=0.7$, a typical rapid leg run event, with a period of nearly constant $q_{\text {peak }}$ in the penetration resistance profile, is observed. Safe installation is possible for thinner normalised sand thickness (e.g., $H_{\mathrm{s}} / D=0.2$ ). While the contribution of clay bearing capacity to the penetration resistance is the same for the cases with the same $s_{\text {um }}$ and $k$, the shearing in the thicker sand provides a much larger contribution to the peak resistance than that from thinner sand, and this leads to more obvious punch-through potential.

\section{Bearing capacity in the underlying clay}




\subsection{Generalised bearing capacity factor}

During spudcan penetration in the underlying clay, the sand underneath is pressed and it forms a composite foundation with the moving spudcan. The bearing capacity factor $N_{\mathrm{c}}$ was derived by dividing the net penetration resistance by the undrained shear strength in the centrifuge tests and LDFE simulations, for which the $N_{\mathrm{c}}$ and $s_{\mathrm{u} 0}$ refer to the values at RP in Fig. 2b. Based on a large dataset of 111 cases, Hu et al. (2015a) derived an equation that fits all the data as:

$$
N_{\mathrm{c}}=10.5+11 \frac{H_{\mathrm{s}}}{D}
$$

When the additional 32 data in this study are added to the previous (forming a new database of 143cases), it was found that Eq. (1) over-predicted the bearing capacity factor for $\mathrm{kD} / \mathrm{s}_{\mathrm{um}}<$ 1.0 (most cases in this study). This indicates the bearing capacity factor $N_{\mathrm{c}}$ also has a correlation with the profile of the shear strength of clay and to improve the prediction method this should be incorporated in the expression for $N_{\mathrm{c}}$.

To improve the prediction for the underlying stiff clay cases, the bearing capacity factor was fitted to $\mathrm{Hu}$ et al. method and it shows linear relationship against the normalised sand thickness and normalised shear strength of clay with the optimal expression determined to be:

$$
N_{\mathrm{c}}=\left(9+0.9 \frac{k D}{s_{\mathrm{um}}}\right)+\left(10+\frac{k D}{s_{\mathrm{um}}}\right) \frac{H_{\mathrm{s}}}{D} \quad\left(\text { for } \quad 0 \leq \frac{k D}{s_{\mathrm{um}}} \leq 3\right)
$$

The predictions of $N_{\mathrm{c}}$ with $k D / s_{\mathrm{um}}$ in the range of $0-3$ from Eq. (2) and the predictions from Eq. (1) are plotted together in Fig. 12. It can be seen that both Equations provide a similar trend and there is minor difference for the bearing capacity factors on sand over soft clay $\left(k D / s_{\mathrm{um}}=1\right.$ and 2$)$ soils. However, Eq. (2) explicitly incorporating the effect of shear strength of clay, which is a generalised expression with more flexibility of estimating the bearing capacity factor, especially for underlying clay with very low or high undrained shear strength. 
The expression for bearing capacity factor is verified by comparison with those from the new database, plotting in terms of $N_{\mathrm{c}, \text { predicted }} / N_{\mathrm{c} \text {, test }}\left(N_{\mathrm{c}, \text { numerical }}\right)$ against $H_{\mathrm{s}} / D$ ratio, as shown in Fig. 13. By assuming $N_{\mathrm{c}}$ follows a normal distribution, the variability of $N_{\mathrm{c}}$ due to the scatter of the data points is expressed by its mean (from Eq. 2) and bounds represented by its standard deviation. The new expression provides an average of all the predictions of $N_{\mathrm{c} \text {, predicted }} / N_{\mathrm{c} \text {, test }}$ $\left(N_{\mathrm{c}, \text { numerical }}\right)$ of 0.99 and a $\sigma$ of 0.08 . It could also be seen that the majority of the predictions are within $\pm 1 \sigma$ of the values in the database. The coefficient of variation $(\mathrm{COV})$ is $7.9 \%$, manifesting low variation. The skew angle of the linear regression line is only $-1.8^{\circ}$, indicating Eq. 2 is capable of effectively predicting $N_{\mathrm{c}}$ over the range of $H_{\mathrm{s}} / D$ of practical interest.

\subsection{Validation of the new bearing capacity factor expression}

The penetration resistance-depth profiles of six centrifuge tests were re-calculated using the $\mathrm{Hu}$ et al. method with the new bearing capacity factor expression and the new comparisons are shown in Fig. 14. It can be seen that the predictions for the profiles of the underlying clay are improved, especially for the stiff clay tests SP1-SP3. This indicates that although the Hu et al. method was originally calibrated from soft clay soils, the new bearing capacity factor with explicit inclusion of the $\mathrm{kD} / \mathrm{s}_{\mathrm{um}}$ gradients enables it to predict relatively stiffer soils.

The three sand overlying stiff clay tests SP1-SP3 are further used in this investigation to validate the performance of the proposed $N_{\mathrm{c}}$ equation. The predictions of the penetration resistance in clay in terms of $q_{\text {prediction }} / q_{\text {test }}$ from ISO (2012) guideline and the $\mathrm{Hu}$ et al. method with both the original and new bearing capacity factor expression are plotted and compared in Fig. 15. The expression for $N_{\mathrm{c}}$ given in Houlsby and Martin (2003) was recommended by the ISO guideline and it is used in this comparison. It is obvious that the previous bearing capacity factor expression of $\mathrm{Hu}$ et al. (2015a), as expressed in Eq. (1), over-estimates the penetration resistance by as much as $40 \%$ for these cases of low $\mathrm{kD} / \mathrm{s}_{\mathrm{um}}$ 
gradients. The discrepancy is due to the bearing capacity factor expression not being calibrated on stiff soils (and the previous expression averaging tests with higher $\mathrm{kD} / \mathrm{sum}_{\mathrm{um}}$ gradients). The ISO (2012) method under-estimates the penetration resistance by $\sim 40 \%$. This is because the factors of Houlsby and Martin do not consider the sand plug trapped beneath the spudcan, which mobilises a higher shear strength of clay with a larger failure mechanism and further frictional resistance around the periphery of the sand plug. The predictions from the new expression of Eq. (2) generally capture the trend of the test results, though a slight under-prediction is noticed.

When predicting the full penetration resistance profile for spudcan installation in sand overlying clay soils using the $\mathrm{Hu}$ et al. method, it is recommended that the new bearing capacity factor expression (Eq. 2) is used.

\section{Conclusions}

Six centrifuge tests have been conducted using a beam centrifuge to investigate spudcan foundation behaviour in sand overlying stiff clay. In contrast to previous soft clays testing database, the terminology "stiff clay" is adopted in this paper for the clays with strength greater than $40 \mathrm{kPa}$. The tests covered different prototype sand thicknesses of 4 and $6 \mathrm{~m}$ and spudcan diameters in the range of 6 to $12 \mathrm{~m}$, corresponding to $H_{\mathrm{s}} / D$ ratios of 0.33 to 1 . The CEL approach was used to replicate the centrifuge tests and to extend the database by a further 20 cases. Interpretation of the testing and numerical data has led to the following conclusions:

- The modified failure stress dependent model in the $\mathrm{Hu}$ et al. method is capable of accurately predicting the peak penetration resistance $q_{\text {peak }}$ for sand overlying stiff clay.

- The two methods recommended in ISO (2012) under predict the six experimentally measured $q_{\text {peak }}$ values. 
- Both the original $\mathrm{Hu}$ et al. method and ISO (2012) have difficulty predicting the spudcan resistance in the underlying stiff clay when the $k D / s_{\text {um }}$ gradient is low, with the original bearing capacity factor expression of $\mathrm{Hu}$ et al. causing an over-estimate. A new expression for the bearing capacity factor is proposed. It is written as a function of the normalised sand thickness $H_{s} / D$ and the undrained shear strength gradient $\mathrm{kD} / \mathrm{s}_{\text {um }}$ gradients of the clay.

\section{Acknowledgements}

This work forms part of the activities of the Centre for Offshore Foundation Systems (COFS), which is supported by the Lloyd's Register Foundation as a Centre of Excellence and currently forms one of the primary nodes of the Australian Research Council (ARC) Centre of Excellence for Geotechnical Science and Engineering. Lloyd's Register Foundation invests in science, engineering, and technology for public benefit, worldwide. This project received additional support from the ARC Laureate Fellowship (FL130100059). The authors are grateful for this support and also to beam centrifuge technician Mr. Manuel Palacios for his assistance during the experimental work and for fruitful discussions with David Edwards in DNV GL and Youhu Zhang in the Norwegian Geotechnical Institute regarding this work. 


\section{References}

Cassidy, M.J. (2012). Experimental observation of the penetration of spudcan footings in silt. Géotechnique, 62(8), 727-732.

Cassidy, M.J., Byrne, B.W., and Randolph, M.F. (2004). A comparison of the combined load behaviour of spudcan and caisson foundations on soft normally consolidated clay. Géotechnique, 54(2), 91-106.

Chung, S.F., Randolph, M.F., and Schneider, J.A. (2006). Effect of penetration rate on penetrometer resistance. Journal of Geotechnical and Geoenvironmental Engineering, ASCE, 132(9), 1188-1196.

Craig, W.H., and Chua, K. (1990). Deep penetration of spudcan foundations on sand and clay. Géotechnique, 40(4), 541-556.

Finnie, I.M.S., and Randolph, M.F. (1994). Punch-through and liquefaction induced failure of shallow foundations on calcareous sediments. Proceedings of the 7th International Conference on the Behaviour of Offshore Structures, Boston, 217-230.

Hodder, M.S., White, D.J., and Cassidy, M.J. (2010). Analysis of soil strength degradation during episodes of cyclic loading, illustrated by the T-Bar penetration test. International Journal of Geomechanics, 10(3), 117-123.

Hossain, M.S., Hu, Y., and Ekaputra, D. (2016). Extraction response of skirted foundation and a spudcan on sand-over-clay deposits, Géotechnique, DOI: http://dx.doi.org/10.1680/jgeot.16.T.018.

Houlsby, G.T., and Martin, C.M. (2003). Undrained bearing capacity factors for conical footings on clay. Géotechnique, 53(5), 513-520.

Hu, P., Stanier, S.A., Cassidy, M.J., and Wang, D. (2014a). Predicting peak resistance of spudcan penetrating sand overlying clay. Journal of Geotechnical and Geoenvironmental Engineering, ASCE, 140(2), 04013009.

Hu, P., Wang, D., Cassidy, M.J., and Stanier, S.A. (2014b). Predicting the resistance profile of spudcan on sand overlying clay. Canadian Geotechnical Journal, 51(10), 1151-1164.

Hu, P., Wang, D., Stanier, S.A., and Cassidy, M.J. (2015a). Assessing the punch-through hazard of a spudcan on sand overlying clay. Géotechnique, 65(11), 883-896. 
Hu, P., Stanier, S.A., Wang, D., and Cassidy, M.J. (2015b). A comparison of full profile prediction methods for a spudcan penetrating sand overlying clay, Géotechnique Letters, 5(3), 131-139.

Hu, P., Stanier, S.A., Wang, D., and Cassidy, M.J. (2016). Effect of footing shape on penetration in sand overlying clay. International Journal of Physical Modelling in Geotechnics, 16(3), 119-133.

International Organization for Standardization (ISO). (2012). Petroleum and natural gas industries - Site-specific assessment of mobile offshore unit-Part 1: Jack-ups. ISO, Geneva, ISO/FDIS 19905-1.

Kellezi, L., Kudsk, G., and Hansen, P.B. (2005). FE modelling of spudcan - pipeline interaction. Proceedings of the International Symposium on Frontiers in Offshore Geotechnics (ISFOG), Perth, 551-557.

Kellezi, L., and Stadsgaard, H. (2012). Design of Gravel Banks - a Way to Avoid Jack-up Spudcan Punch-Through Type of Failure. Proceedings of the Offshore Technology Conference, Houston, Texas, OTC-23184.

Lee, K. K. (2009). Investigation of potential spudcan punch-through failure on sand overlying clay soils. Ph.D. thesis, University of Western Australia, Perth, Australia.

Lee, K.K., Cassidy, M.J., and Randolph, M.F. (2013a). Bearing capacity on sand overlying clay soils: Experimental and finite element investigation of potential punch-through failure. Géotechnique, 63(15), 1271-1284.

Lee, K.K., Randolph, M.F., and Cassidy, M.J. (2013b). Bearing capacity on sand overlying clay soils: A simplified conceptual model. Géotechnique, 63(15), 1285-1297.

Mana, D.S.K., Gourvenec, S., Randolph, M.F., and Hossain, M.S. (2012). Failure mechanisms of skirted foundations in uplift and compression. International journal of Physical Modelling in Geotechnics, 12(2), 47-62.

Martin, C.M., and Houlsby, G.T. (2000). Combined loading of spudcan foundations on clay: laboratory tests. Géotechnique, 50(4), 325-338. 
Osborne, J.J., Teh, K.L., Leung, C.F., Cassidy, M.J., Houlsby, G.T., Chan, N., Devoy, D., Handidjaja, P., and Foo, K.S. (2008). An introduction to the InSafe JIP. Proceedings of the 2nd Jack-up Asia Conference, Singapore.

Qiu, G., and Grabe, J. (2012). Numerical investigation of bearing capacity due to spudcan penetration in sand overlying clay. Canadian Geotechnical Journal, 49(12), 1393-1407.

Qiu, G., and Henke, S. (2011). Controlled installation of spudcan foundations on loose sand overlying weak clay. Marine Structures, 24(4), 528-550.

Randolph, M.F. (2004). Characterisation of soft sediments for offshore applications. The 2nd International Conference on Site Characterization, Rotterdam, The Netherlands, 1, 209232.

Teh, K.L. (2007). Punch-through of spudcan foundation in sand overlying clay. Ph.D. thesis, National University of Singapore, Singapore.

Teh, K.L., Leung, C.F., Cassidy, M.J., and Chow, Y.K. (2010). Centrifuge model study of spudcan penetration in sand overlying clay. Géotechnique, 60(11), 825-842.

Tho, K.K., Leung, C.F., Chow, Y.K., and Swaddiwudhipong, S. (2012). Eulerian finite element technique for analysis of jack-up spudcan penetration. International Journal of Geomechanics, 12(1), 64-73.

van Dijk, B.F.J., and Yetginer, A.G. (2015). Findings of the ISSMGE jack-up leg penetration event. Proceedings of the third International Symposium on Frontiers in Offshore Geotechnics (ISFOG 2015), Oslo, Norway, CRC Press, Boca Raton, pp. 1267-1274.

Vlahos, G., Cassidy, M.J., and Martin, C.M. (2011). Numerical simulation of pushover tests on a model jack-up platform on clay. Géotechnique, 61(11), 947-960.

Werno, M., Juszkiewicz-Bednarczyk, B., and Inerowicz, M. (1987). Penetration of jack-up platform footings into the seabed. Marine Geotechnology, 7, 65-78.

Young, A.G., Remmes, B.D., and Meyer, B.J. (1984). Foundation performance of offshore jack-up drilling rigs. Journal of Geotechnical Engineering Division, ASCE, 110(7), 841-859. 


\section{List of Figures}

Fig. 1. Record of jack-up spudcan bearing pressures

Fig. 2. Model spudcan foundations and dimensions: (a) Model spudcans used in beam centrifuge experiments; (b) dimensions of model spudcans (in model scale)

Fig. 3. Surcharging clay using steel beams: (a) soil sample covered by brass mesh and geofabric; (b) layout of steel beams above the brass mesh

Fig. 4. Shear strength profile of underlying clay from T-bar tests

Fig. 5. Clay sensitivity from cyclic T-bar tests

Fig. 6. Penetration profiles for spudcan foundations in $6 \mathrm{~m}$ prototype sand thickness

Fig. 7. Penetration profiles for spudcan foundations in $4 \mathrm{~m}$ prototype sand thickness

Fig. 8. Comparison of measured and calculated $q_{\text {peak }}$

Fig. 9. Experimental, predicted and simulated spudcan penetration resistance profiles: (a) SP1 and SP4; (b) SP2 and SP5; (c) SP3 and SP6

Fig. 10. Deformed soils and clay shear strength contour (case PS12)

Fig. 11. Factors influencing the penetration resistance profiles: (a) effect of $s_{\text {um }}$; (b) effect of $H_{\mathrm{s}} / D$

Fig. 12. Bearing capacity factors from the experimental and numerical analyses database

Fig. 13. Verification of the new expression by comparing with the database

Fig. 14. Experimental and updated predicted spudcan penetration resistance profiles: (a) SP1 and SP4; (b) SP2 and SP5; (c) SP3 and SP6

Fig. 15. Performance of the new bearing capacity factor expression 
Table 1 Summary of sand-over-clay centrifuge tests reported in the literature

\begin{tabular}{c|c|c|c|c|c}
\hline \multirow{2}{*}{ Investigation } & \multirow{2}{*}{$\begin{array}{c}\text { Centrifuge } \\
\text { type }\end{array}$} & \multirow{2}{*}{$\begin{array}{c}\text { Number } \\
\text { of tests }\end{array}$} & \multicolumn{3}{|c}{ Clay property } \\
\cline { 4 - 6 } & & $\boldsymbol{s u m}(\mathbf{k P a})$ & $\boldsymbol{k}(\mathbf{k P a} / \mathbf{m})$ & $\boldsymbol{k D / s u m}$ \\
\hline Lee (2009) UWA Tests & beam & 5 & 13.2 & 1.9 & $1.1-2.0$ \\
\hline Teh et al. (2010) NUS Tests & beam & 7 & $7.8-25.8$ & 1.6 & $0.6-2.0$ \\
\hline Teh et al. (2010) UWA Tests & beam & 3 & $7.2-14.6$ & 1.2 & $0.7-1.0$ \\
\hline Lee et al. (2013) UWA Tests & drum & 30 & $16.3-19.1$ & 2.1 & $0.6-2.0$ \\
\hline Hu et al. (2014) UWA Tests & drum & 15 & $11.0-13.0$ & $1.5-1.6$ & $0.7-2.8$ \\
\hline Hu et al. (2016) UWA Tests & drum & 11 & $11.3-22.2$ & $1.5-2.1$ & $0.8-1.1$ \\
\hline Hossain et al. (2016) UWA Tests & drum & 6 & 23.5 & 0 & 0 \\
\hline Summary & beam/drum & 77 & $7.2-25.8$ & $0-2.1$ & $0-2.8$ \\
\hline
\end{tabular}

Table 2 Engineering properties of super fine silica sand and kaolin clay

\begin{tabular}{|c|c|c|c|}
\hline Soil & Property & Symbol & Value \\
\hline \multirow{6}{*}{ Super fine silica sand } & Specific gravity & $G_{\mathrm{s}}$ & 2.65 \\
\hline & Median particle size & $d_{50}(\mathrm{~mm})$ & 0.19 \\
\hline & Effective particle size & $d_{10}(\mathrm{~mm})$ & 0.099 \\
\hline & Maximum void ratio & $e_{\max }$ & 0.7472 \\
\hline & Minimum void ratio & $e_{\min }$ & 0.4485 \\
\hline & Critical state friction angle & $\phi_{\mathrm{cv}}\left(^{\circ}\right)$ & 31 \\
\hline \multirow{9}{*}{ Kaolin clay } & Liquid limit & LL & 0.61 \\
\hline & Plastic limit & PL & 0.27 \\
\hline & Plasticity index & PI & 0.34 \\
\hline & Specific gravity & $G_{\mathrm{s}}$ & 2.6 \\
\hline & Angle of internal friction & $\phi^{\prime}\left(^{\circ}\right)$ & 23.5 \\
\hline & Critical state friction constant & $M$ & 0.92 \\
\hline & Slope of normal consolidation line & $\lambda$ & 0.207 \\
\hline & Slope of swelling line & $k$ & 0.044 \\
\hline & Coefficient of consolidation & $c_{\mathrm{V}}\left(\mathrm{m}^{2} /\right.$ year $)$ & 2 \\
\hline
\end{tabular}

Table 3 Summary of spudcan penetration tests and results as conducted in the centrifuge

\begin{tabular}{|c|c|c|c|c|c|c|c|c|c|c|c|}
\hline \multirow{3}{*}{$\begin{array}{c}\text { Test } \\
\text { name }\end{array}$} & \multicolumn{5}{|c|}{ Geometry } & Sand & \multicolumn{3}{|c|}{ Clay } & \multicolumn{2}{|c|}{ Result } \\
\hline & \multicolumn{2}{|c|}{ Diameter } & \multicolumn{2}{|c|}{$\begin{array}{c}\text { Sand } \\
\text { thickness }\end{array}$} & \multirow[b]{2}{*}{$H_{\mathrm{s}} / D$} & \multirow[b]{2}{*}{$I_{\mathrm{D}}$} & \multirow{2}{*}{$\begin{array}{c}S_{\mathrm{um}} \\
(\mathrm{kPa})\end{array}$} & \multirow{2}{*}{$\begin{array}{c}k \\
(\mathrm{kPa} / \mathrm{m})\end{array}$} & \multirow[b]{2}{*}{$k D / s_{\text {um }}$} & \multirow{2}{*}{$\begin{array}{c}q_{\text {peak, test }} \\
(\mathrm{kPa})\end{array}$} & \multirow{2}{*}{$\begin{array}{c}\text { Installation } \\
\text { resistance, } \\
q_{\text {in }}(\mathrm{kPa})\end{array}$} \\
\hline & $\begin{array}{c}D \\
(\mathrm{~mm})\end{array}$ & $\begin{array}{c}D \\
(\mathrm{~m})\end{array}$ & $\begin{array}{c}H_{\mathrm{s}} \\
(\mathrm{mm})\end{array}$ & $\begin{array}{l}H_{\mathrm{s}} \\
(\mathrm{m})\end{array}$ & & & & & & & \\
\hline SP1 & 30 & 6 & 30 & 6 & 1.00 & 0.65 & 43.9 & 3.4 & 0.46 & 1182.1 & 2059.0 \\
\hline SP2 & 40 & 8 & 30 & 6 & 0.75 & 0.65 & 43.9 & 3.4 & 0.62 & 1052.9 & 1876.8 \\
\hline SP3 & 50 & 10 & 30 & 6 & 0.60 & 0.65 & 43.9 & 3.4 & 0.77 & 895.2 & 1666.7 \\
\hline SP4 & 40 & 8 & 20 & 4 & 0.50 & 0.65 & 32.6 & 3.5 & 0.86 & 633.1 & 1632.6 \\
\hline SP5 & 50 & 10 & 20 & 4 & 0.40 & 0.65 & 32.6 & 3.5 & 1.07 & 611.4 & 1747.3 \\
\hline SP6 & 60 & 12 & 20 & 4 & 0.33 & 0.65 & 32.6 & 3.5 & 1.29 & 542.6 & 1559.8 \\
\hline
\end{tabular}

Note: $k$ corresponds to depth below clay surface. 
Table 4 Summary of numerical CEL simulations

\begin{tabular}{|c|c|c|c|c|c|c|c|c|c|c|c|c|}
\hline- & $\#$ & Name & $\begin{array}{c}D \\
(\mathbf{m})\end{array}$ & $\begin{array}{c}\boldsymbol{H}_{\mathbf{s}} \\
(\mathbf{m})\end{array}$ & $H_{\mathrm{s}} / D$ & $\begin{array}{l}I_{\mathrm{D}} \\
(\%)\end{array}$ & $\begin{array}{c}S_{\mathrm{um}} \\
(\mathrm{kPa})\end{array}$ & $\begin{array}{c}k \\
(\mathrm{kPa} / \mathrm{m})\end{array}$ & $k D / s_{\mathrm{um}}$ & $\begin{array}{c}\varphi_{\text {peak }}^{\prime} \\
\left({ }^{\circ}\right)\end{array}$ & $\begin{array}{c}\psi_{\text {peak }} \\
\left({ }^{\circ}\right)\end{array}$ & $S_{\mathrm{t}}$ \\
\hline \multirow{6}{*}{$\begin{array}{l}\text { Retrospective } \\
\text { simulation of } \\
\text { centrifuge } \\
\text { tests }\end{array}$} & 1 & SP1 & 6 & 6 & 1.00 & 65 & 43.9 & 3.4 & 0.46 & 37.75 & 14.06 & 2.5 \\
\hline & 2 & SP2 & 8 & 6 & 0.75 & 65 & 43.9 & 3.4 & 0.62 & 37.75 & 14.06 & 2.5 \\
\hline & 3 & SP3 & 10 & 6 & 0.60 & 65 & 43.9 & 3.4 & 0.77 & 37.75 & 14.06 & 2.5 \\
\hline & 4 & SP4 & 8 & 4 & 0.50 & 65 & 32.6 & 3.5 & 0.86 & 37.75 & 14.06 & 2.5 \\
\hline & 5 & SP5 & 10 & 4 & 0.40 & 65 & 32.6 & 3.5 & 1.07 & 37.75 & 14.06 & 2.5 \\
\hline & 6 & SP6 & 12 & 4 & 0.33 & 65 & 32.6 & 3.5 & 1.29 & 37.75 & 14.06 & 2.5 \\
\hline \multirow{20}{*}{$\begin{array}{l}\text { Parametric } \\
\text { studies }\end{array}$} & 7 & PS1 & 10 & 7 & 0.70 & 90 & 50.0 & 1.5 & 0.30 & 41.5 & 21.88 & 3 \\
\hline & 8 & PS2 & 16 & 7 & 0.44 & 90 & 50.0 & 1.5 & 0.48 & 41.5 & 21.88 & 3 \\
\hline & 9 & PS3 & 20 & 7 & 0.35 & 90 & 50.0 & 1.5 & 0.60 & 41.5 & 21.88 & 3 \\
\hline & 10 & PS4 & 10 & 7 & 0.70 & 90 & 50.0 & 0.0 & 0.00 & 41.5 & 21.88 & 3 \\
\hline & 11 & PS5 & 10 & 7 & 0.70 & 90 & 80.0 & 0.0 & 0.00 & 41.5 & 21.88 & 3 \\
\hline & 12 & PS6 & 10 & 7 & 0.70 & 90 & 100.0 & 0.0 & 0.00 & 41.5 & 21.88 & 3 \\
\hline & 13 & PS7 & 10 & 7 & 0.70 & 90 & 50.0 & 2.0 & 0.40 & 41.5 & 21.88 & 3 \\
\hline & 14 & PS8 & 10 & 7 & 0.70 & 90 & 50.0 & 5.0 & 1.00 & 41.5 & 21.88 & 3 \\
\hline & 15 & PS9 & 10 & 7 & 0.70 & 50 & 50.0 & 1.5 & 0.30 & 35.5 & 9.38 & 3 \\
\hline & 16 & PS10 & 10 & 7 & 0.70 & 90 & 50.0 & 1.5 & 0.30 & 41.5 & 21.88 & 5 \\
\hline & 17 & PS11 & 10 & 9 & 0.90 & 90 & 50.0 & 1.5 & 0.30 & 41.5 & 21.88 & 3 \\
\hline & 18 & PS12 & 8 & 4 & 0.50 & 90 & 50.0 & 1.5 & 0.24 & 41.5 & 21.88 & 3 \\
\hline & 19 & PS13 & 6 & 6 & 1.00 & 90 & 50.0 & 1.5 & 0.18 & 41.5 & 21.88 & 3 \\
\hline & 20 & PS14 & 10 & 7 & 0.70 & 70 & 50.0 & 1.5 & 0.30 & 38.5 & 15.63 & 3 \\
\hline & 21 & PS15 & 10 & 1 & 0.10 & 90 & 50.0 & 1.5 & 0.30 & 41.5 & 21.88 & 3 \\
\hline & 22 & PS16 & 10 & 2 & 0.20 & 90 & 50.0 & 1.5 & 0.30 & 41.5 & 21.88 & 3 \\
\hline & 23 & PS17 & 10 & 7 & 0.70 & 90 & 50.0 & 1.5 & 0.30 & 41.5 & 21.88 & 1 \\
\hline & 24 & PS18 & 10 & 7 & 0.70 & 30 & 60.0 & 2.0 & 0.33 & 32.5 & 3.13 & 3 \\
\hline & 25 & PS19 & 10 & 7 & 0.70 & 90 & 70.0 & 2.0 & 0.29 & 41.5 & 21.88 & 3 \\
\hline & 26 & PS20 & 10 & 7 & 0.70 & 90 & 90.0 & 2.0 & 0.22 & 41.5 & 21.88 & 3 \\
\hline
\end{tabular}




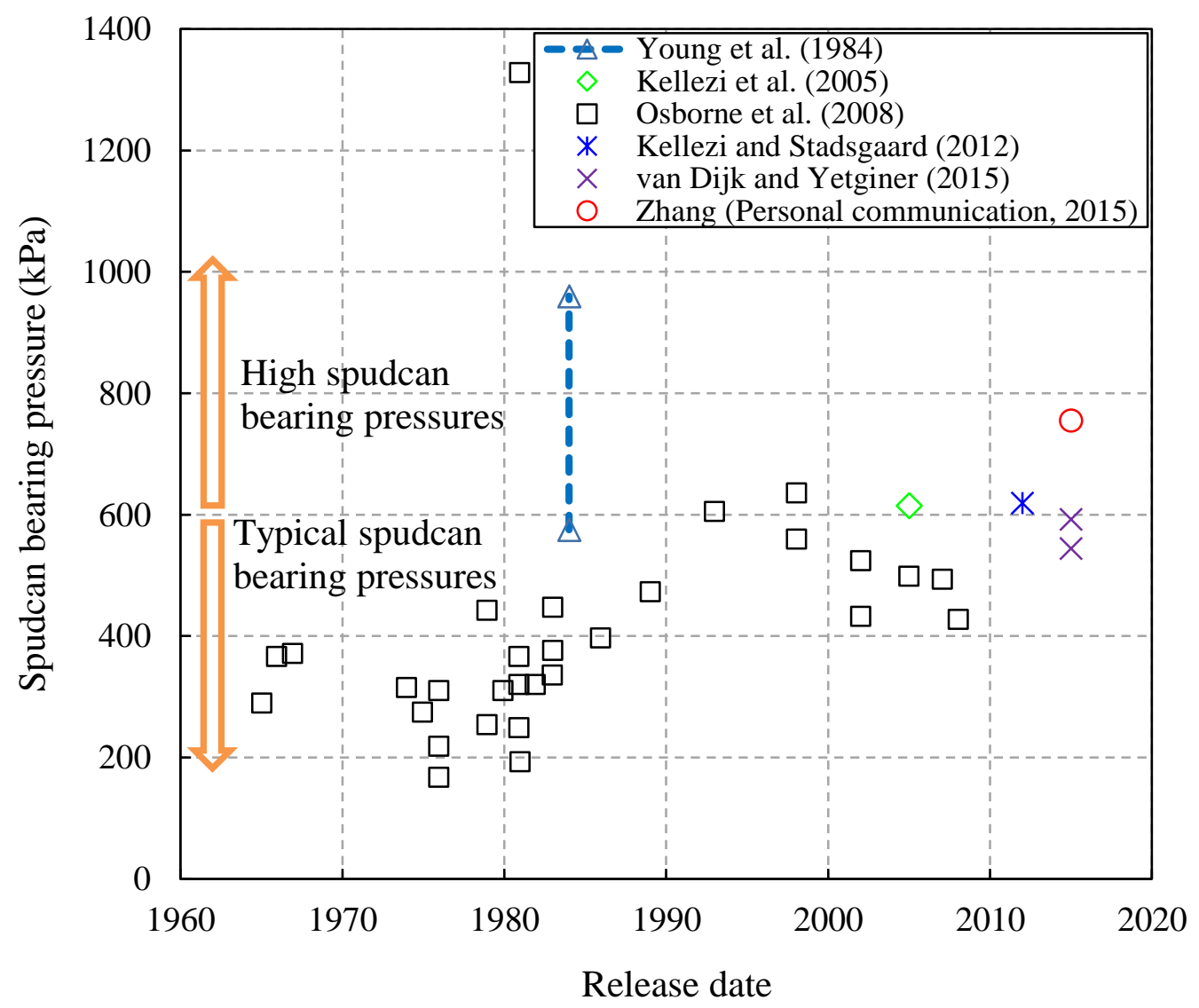

Fig. 1. Record of jack-up spudcan bearing pressures 

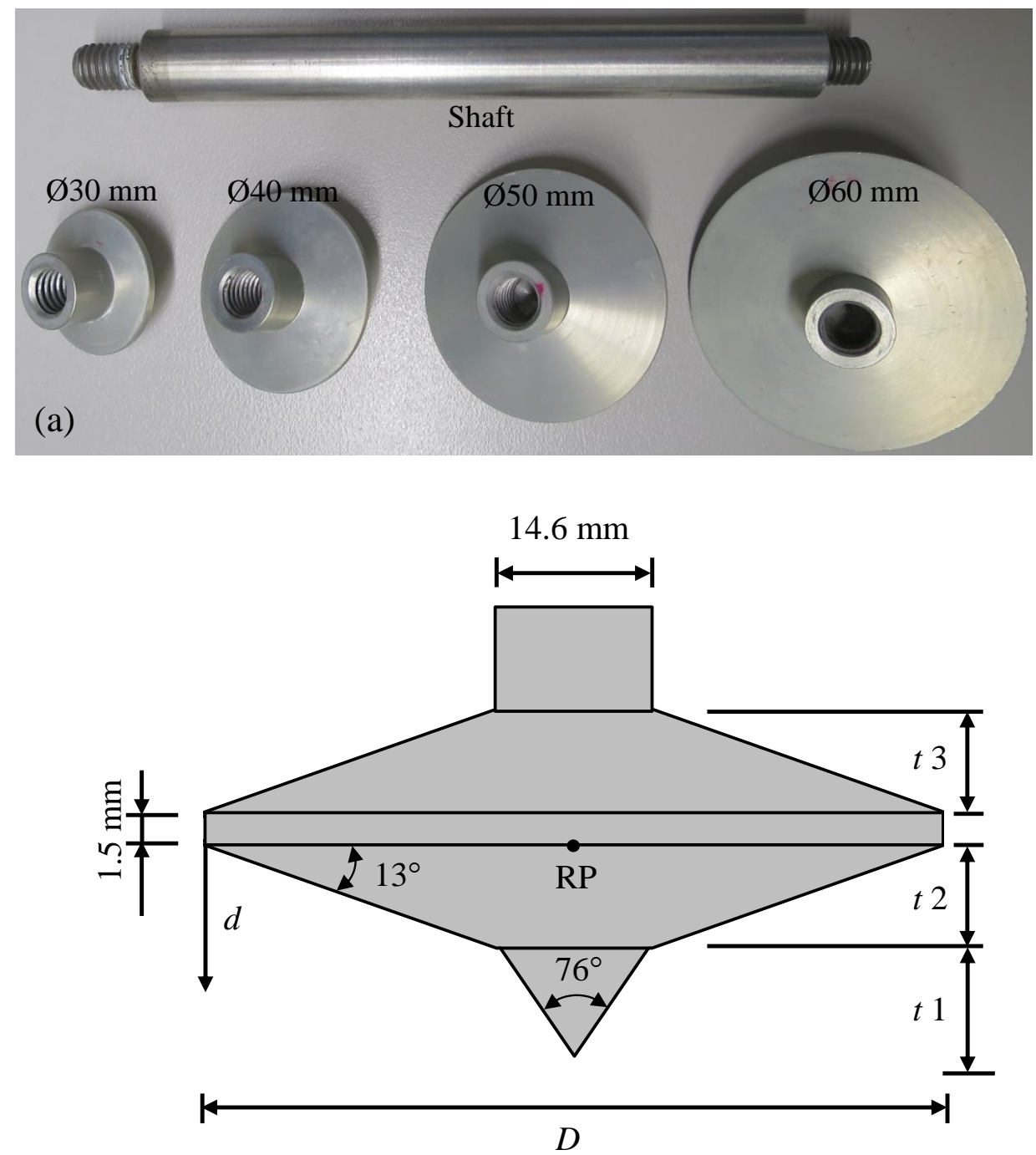

(b)

\begin{tabular}{|c|c|c|c|}
\hline$D(\mathrm{~mm})$ & $t 1(\mathrm{~mm})$ & $t 2(\mathrm{~mm})$ & $t 3(\mathrm{~mm})$ \\
\hline 30 & 4.30 & 2.70 & 1.75 \\
\hline 40 & 5.75 & 3.60 & 2.90 \\
\hline 50 & 7.20 & 4.45 & 4.05 \\
\hline 60 & 8.65 & 5.35 & 5.35 \\
\hline
\end{tabular}

Fig. 2. Model spudcan foundations and dimensions: (a) Model spudcans used in beam centrifuge experiments; (b) dimensions of model spudcans (in model scale) 


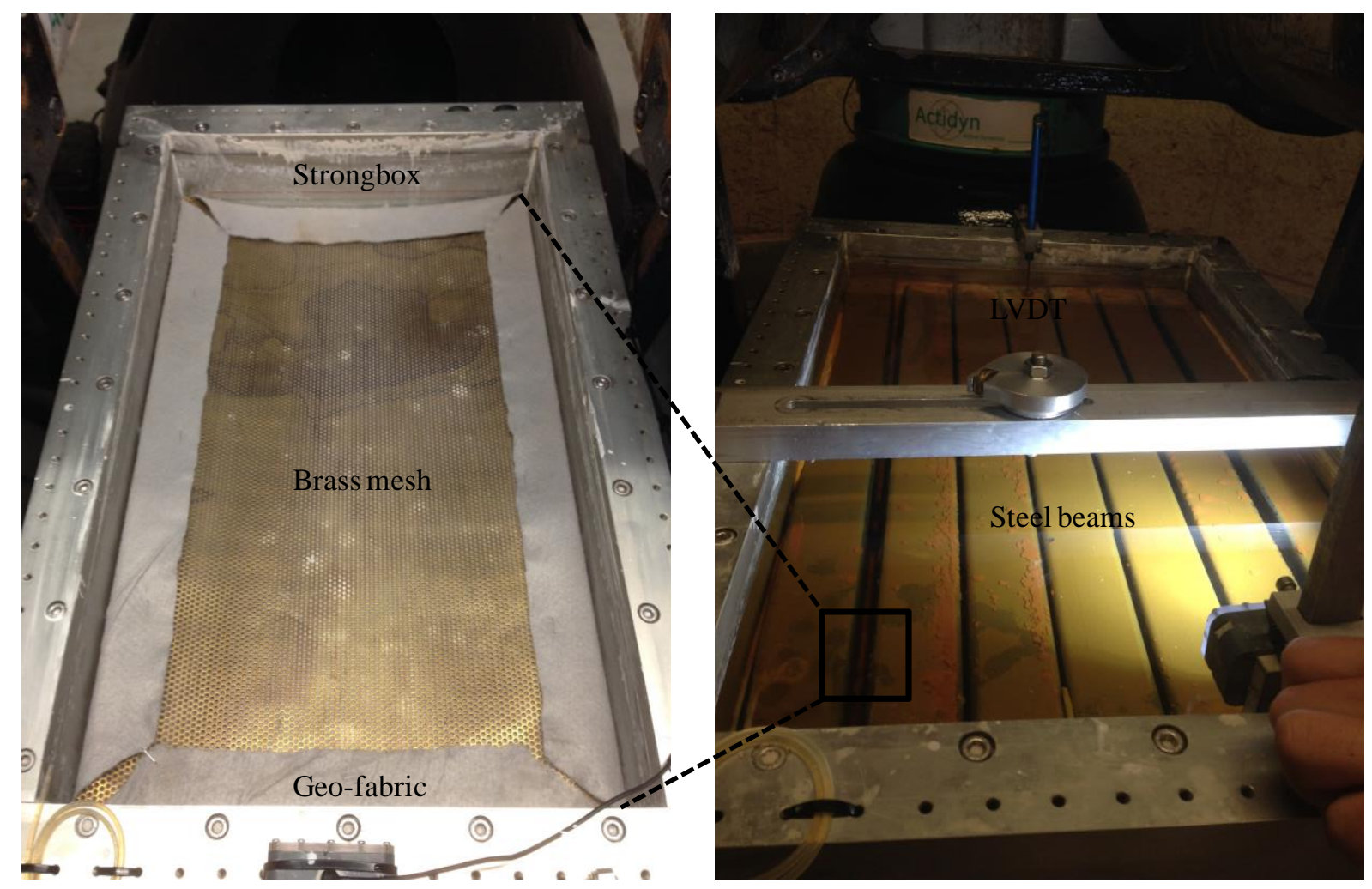

Fig. 3. Surcharging clay using steel beams: (a) soil sample covered by brass mesh and geofabric; (b) layout of steel beams above the brass mesh 


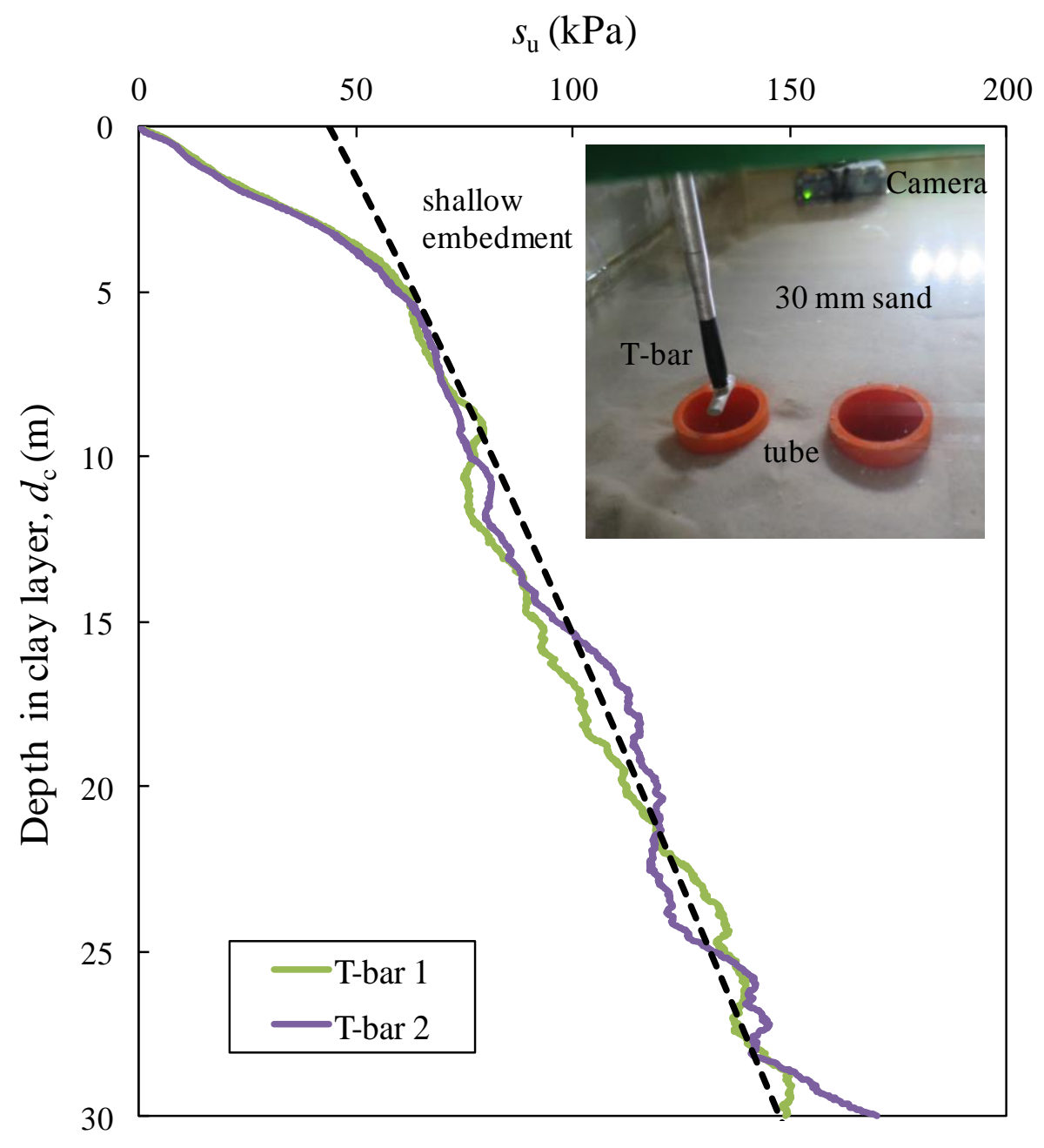

Fig. 4. Shear strength profile of underlying clay from T-bar tests 


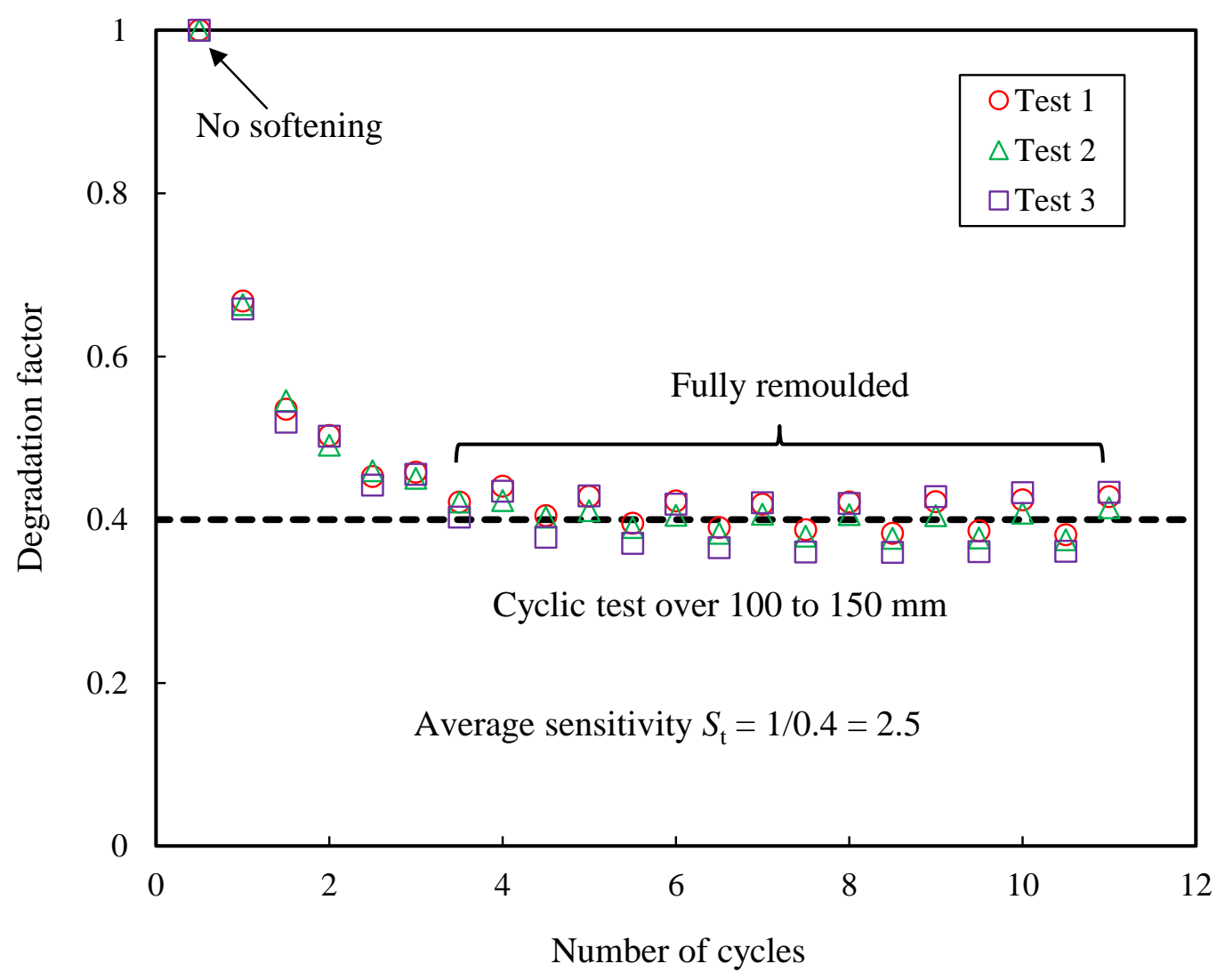

Fig. 5. Clay sensitivity from cyclic T-bar tests 


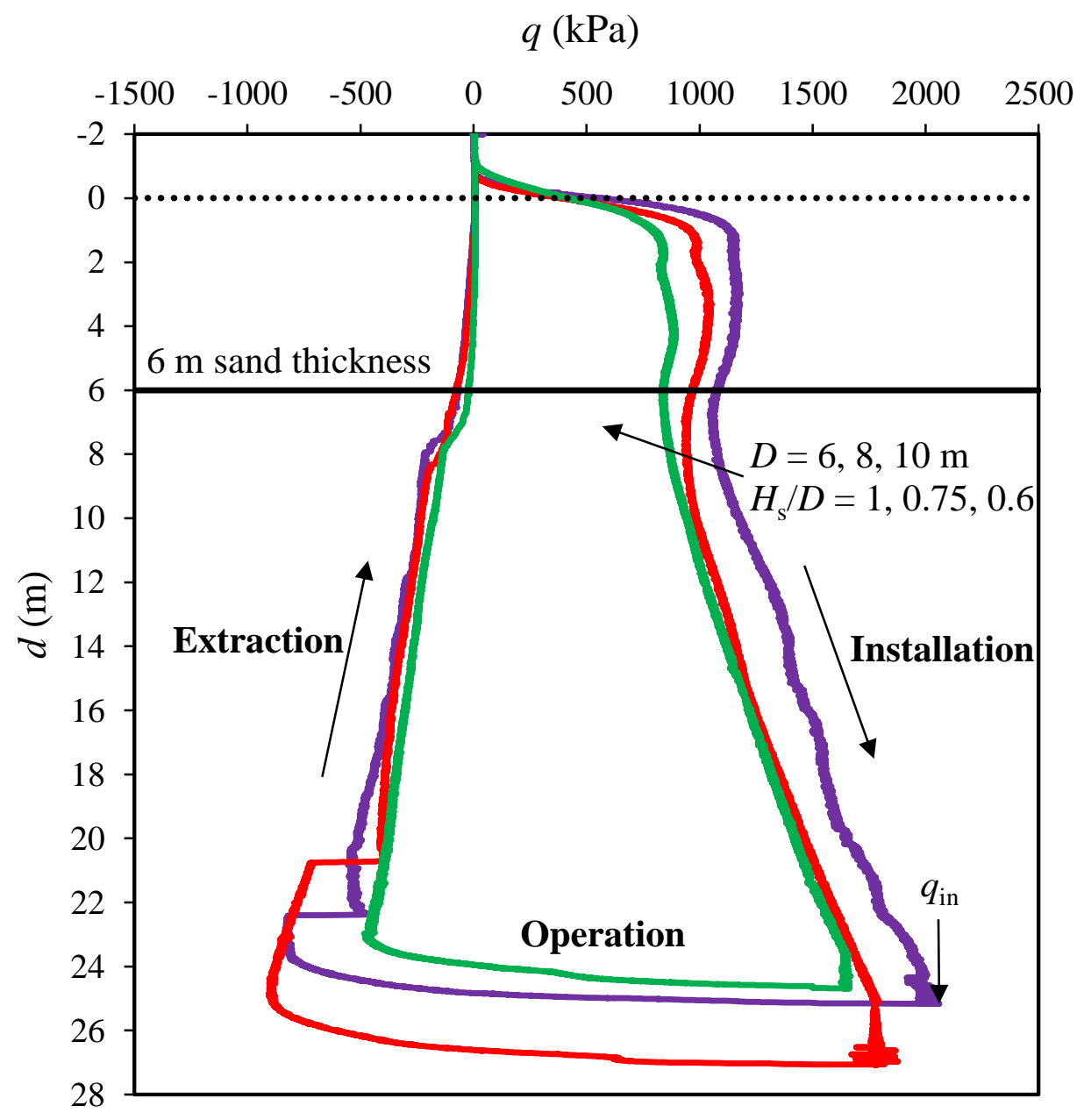

Fig. 6. Penetration profiles for spudcan foundations in $6 \mathrm{~m}$ prototype sand thickness 


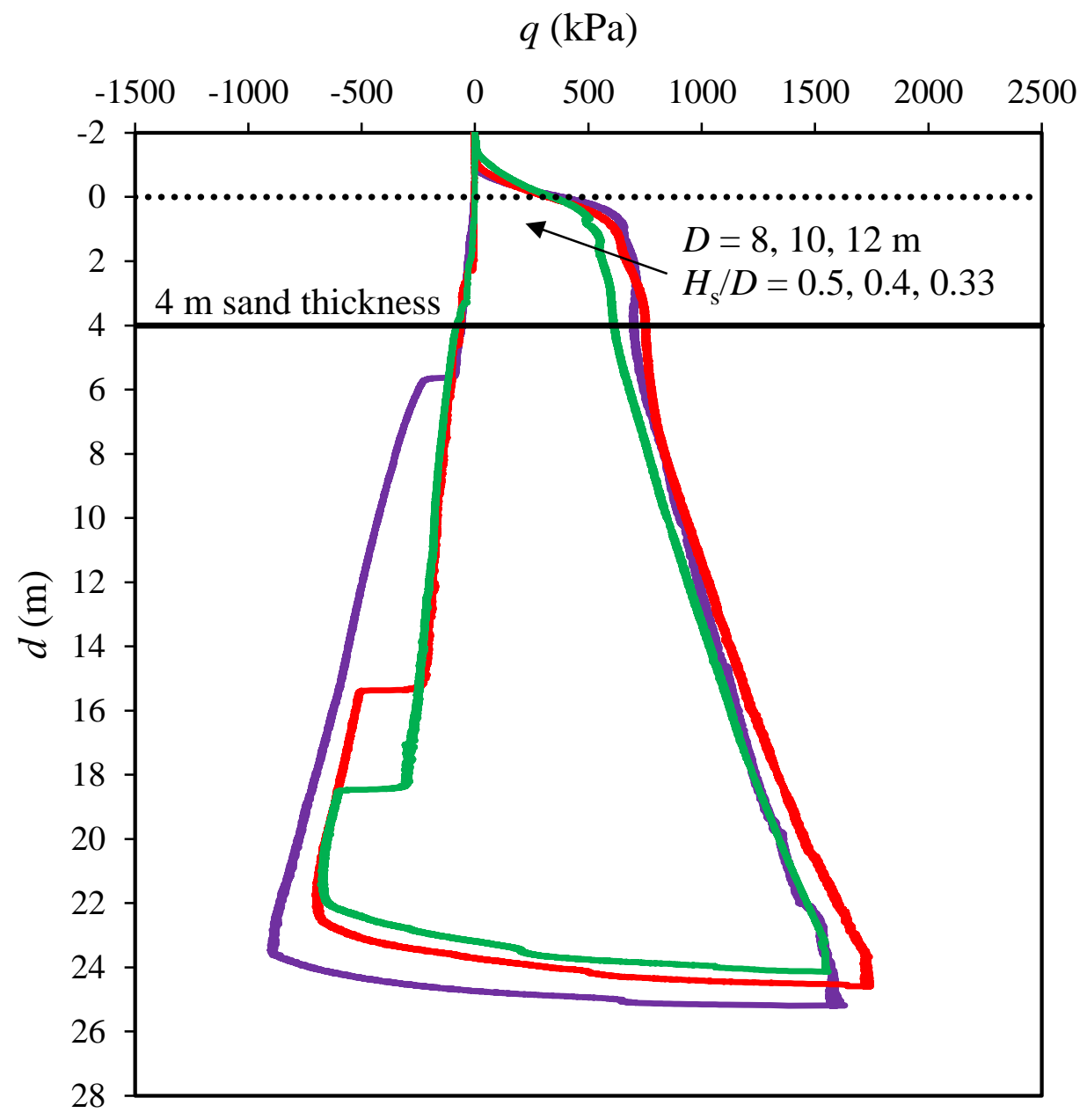

Fig. 7. Penetration profiles for spudcan foundations in $4 \mathrm{~m}$ prototype sand thickness 


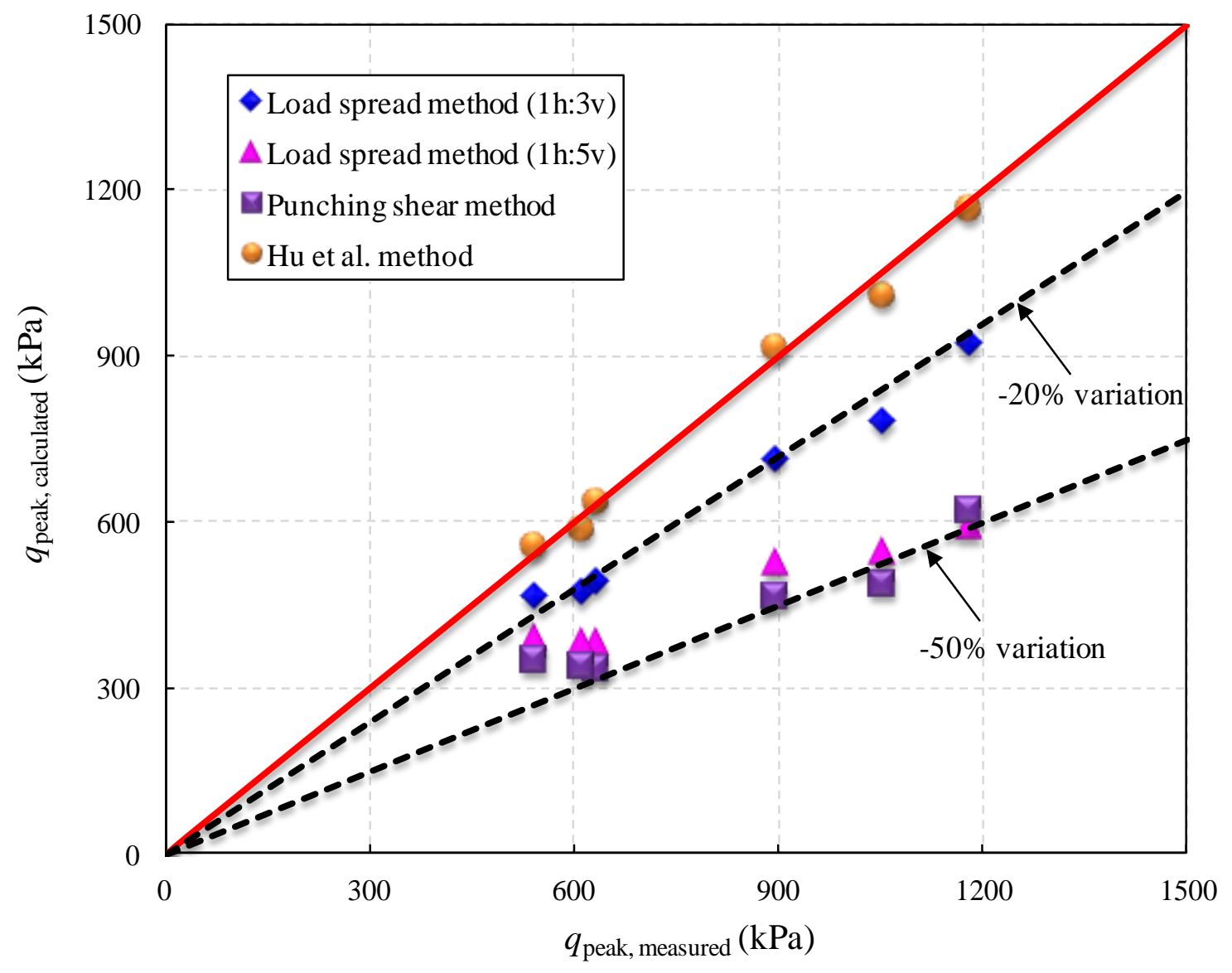

Fig. 8. Comparison of measured and calculated $q_{\text {peak }}$ 

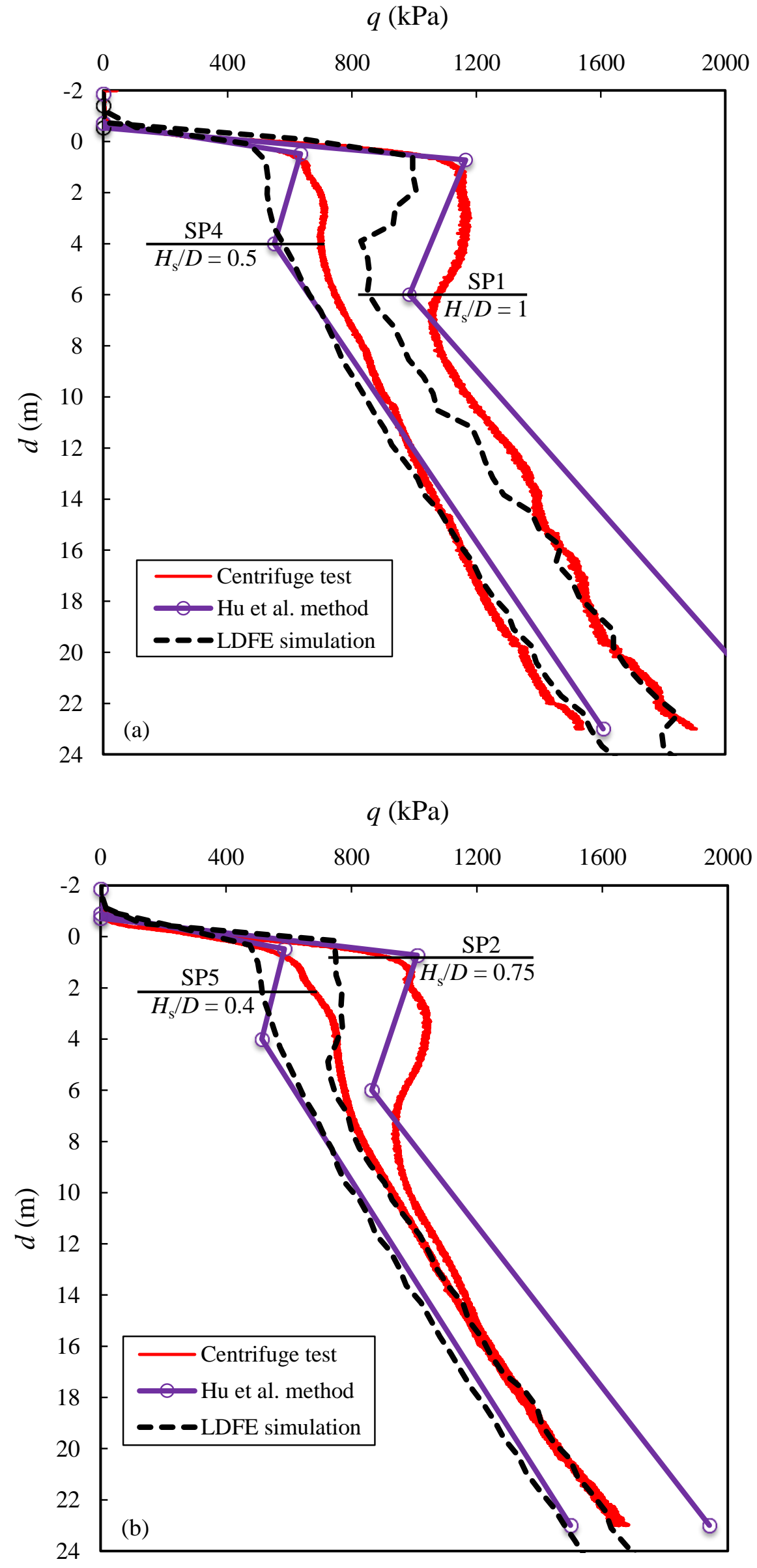


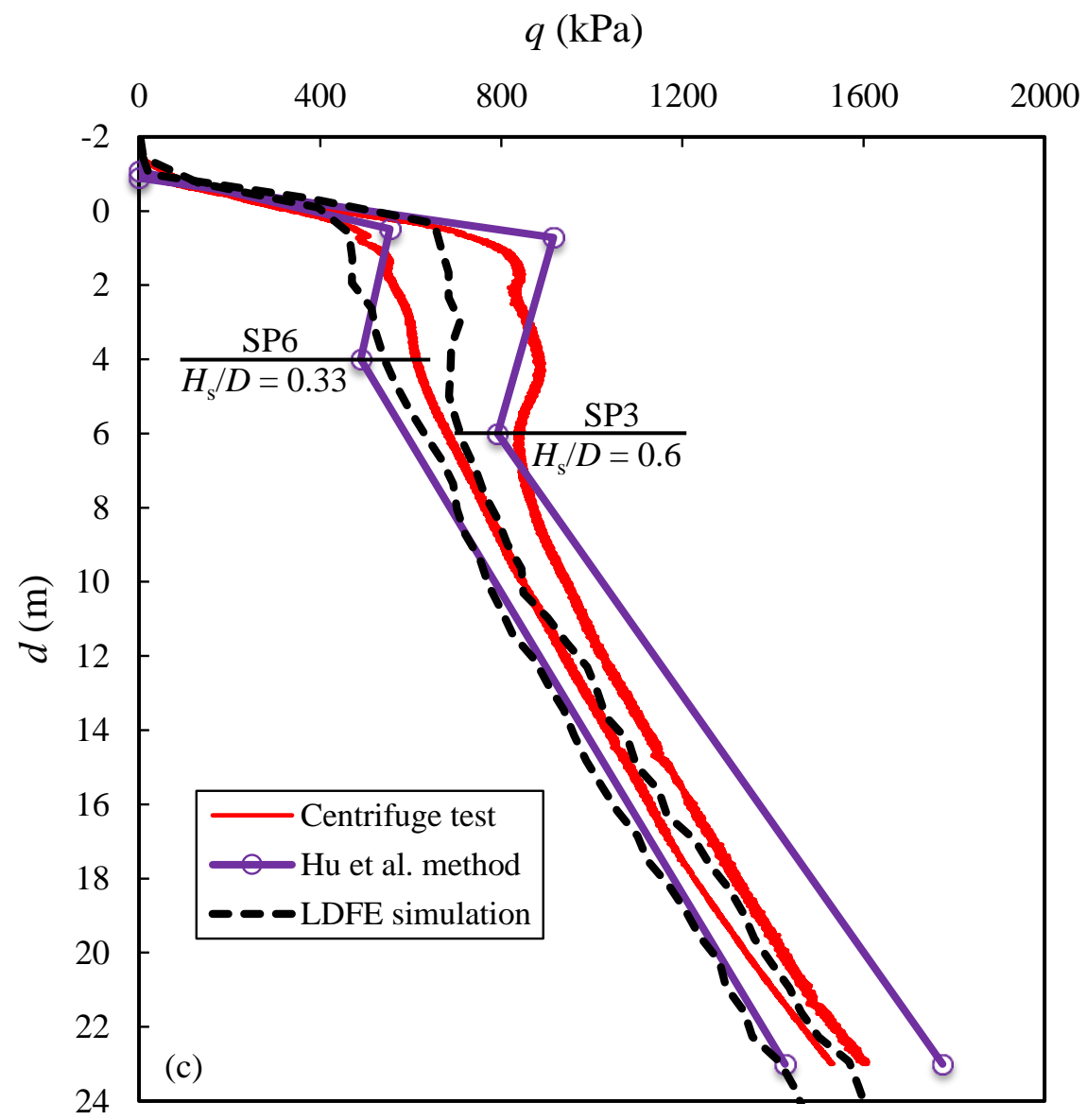

Fig. 9. Experimental, predicted and simulated spudcan penetration resistance profiles: (a) SP1 and SP4; (b) SP2 and SP5; (c) SP3 and SP6 


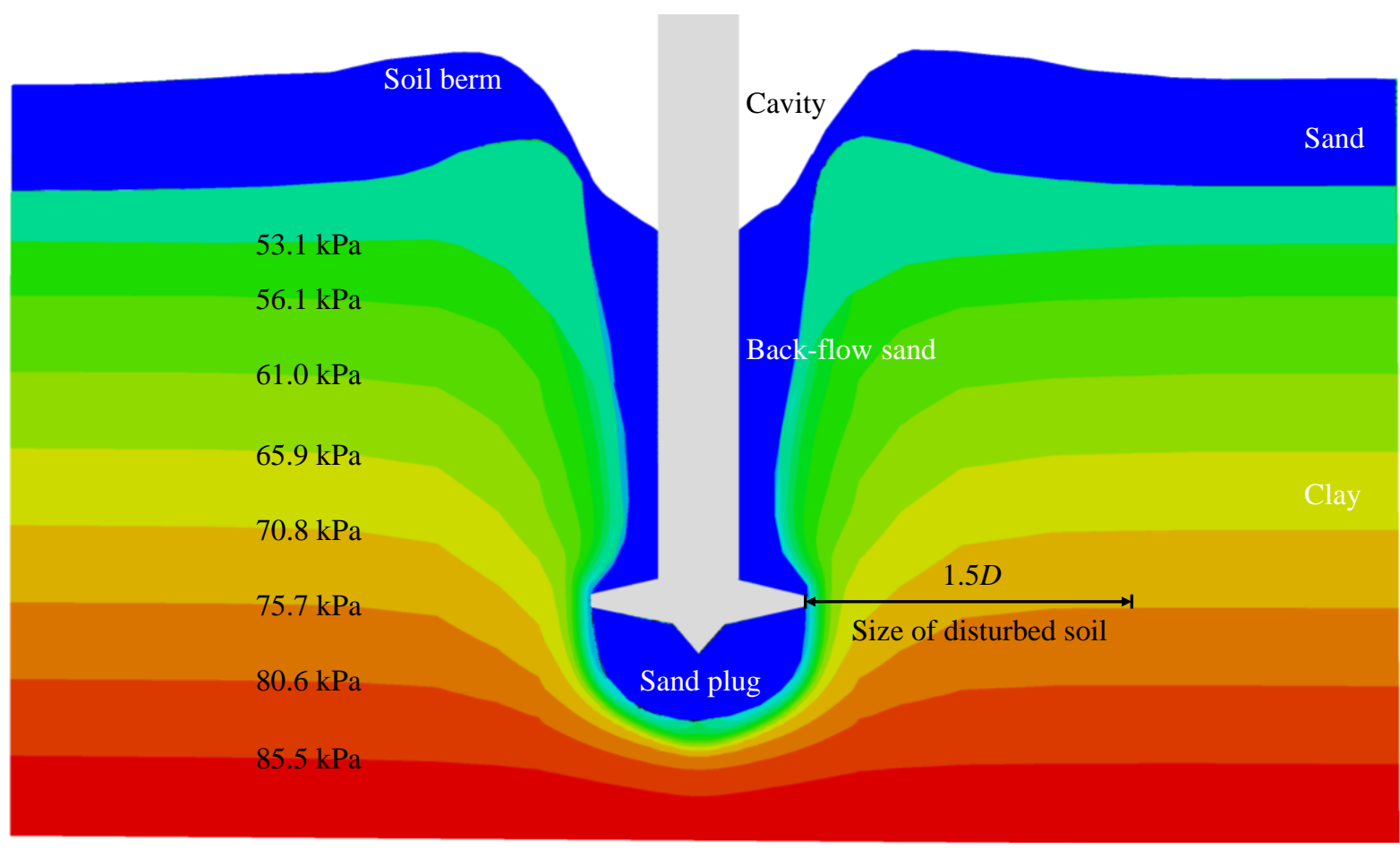

Fig. 10. Deformed soils and clay shear strength contour (case PS12) 

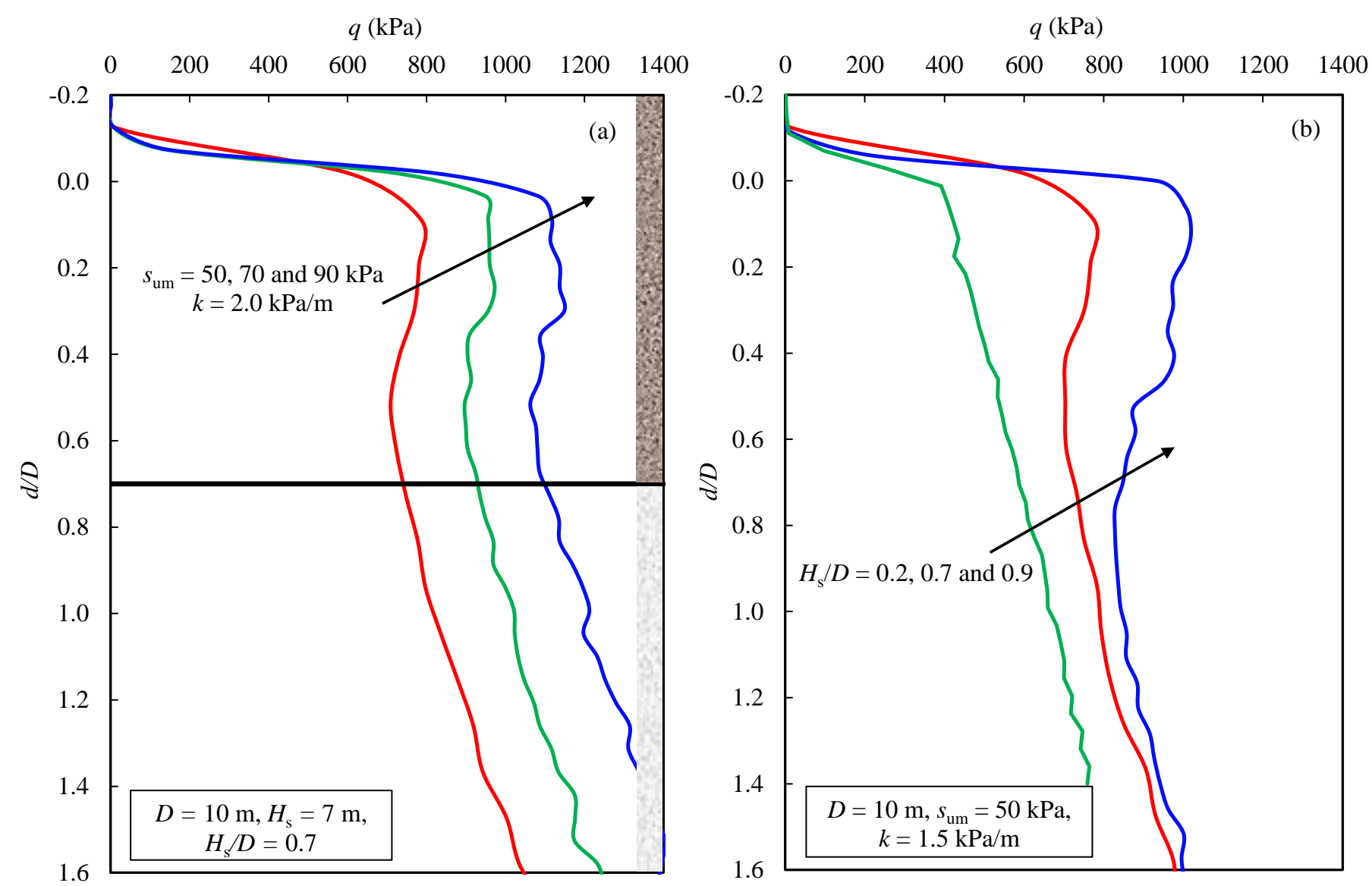

Fig. 11. Factors influencing the penetration resistance profiles: (a) effect of $s_{\text {um }}$; (b) effect of $H_{\mathrm{S}} / D$ 


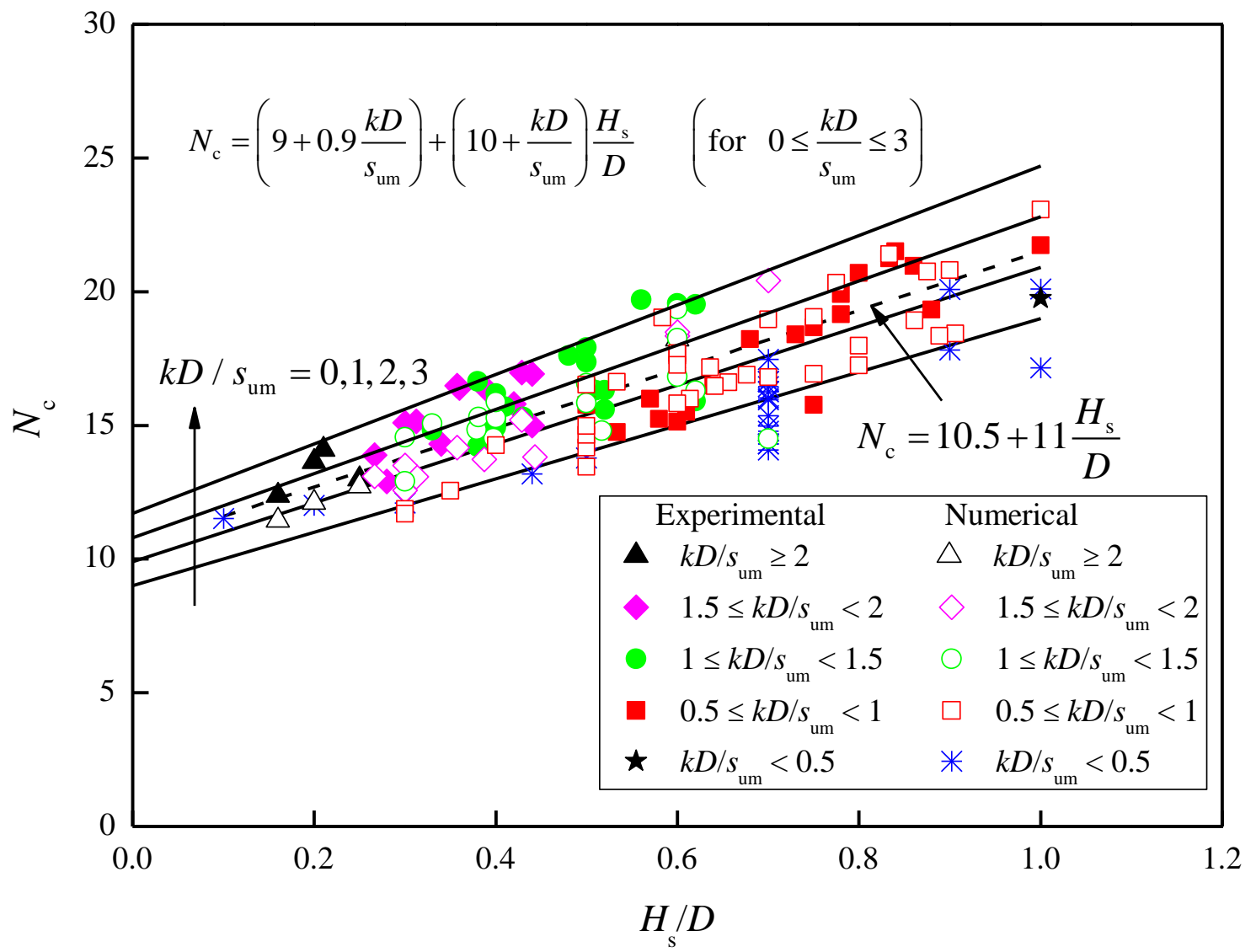

Fig. 12. Bearing capacity factors from the experimental and numerical analyses database 


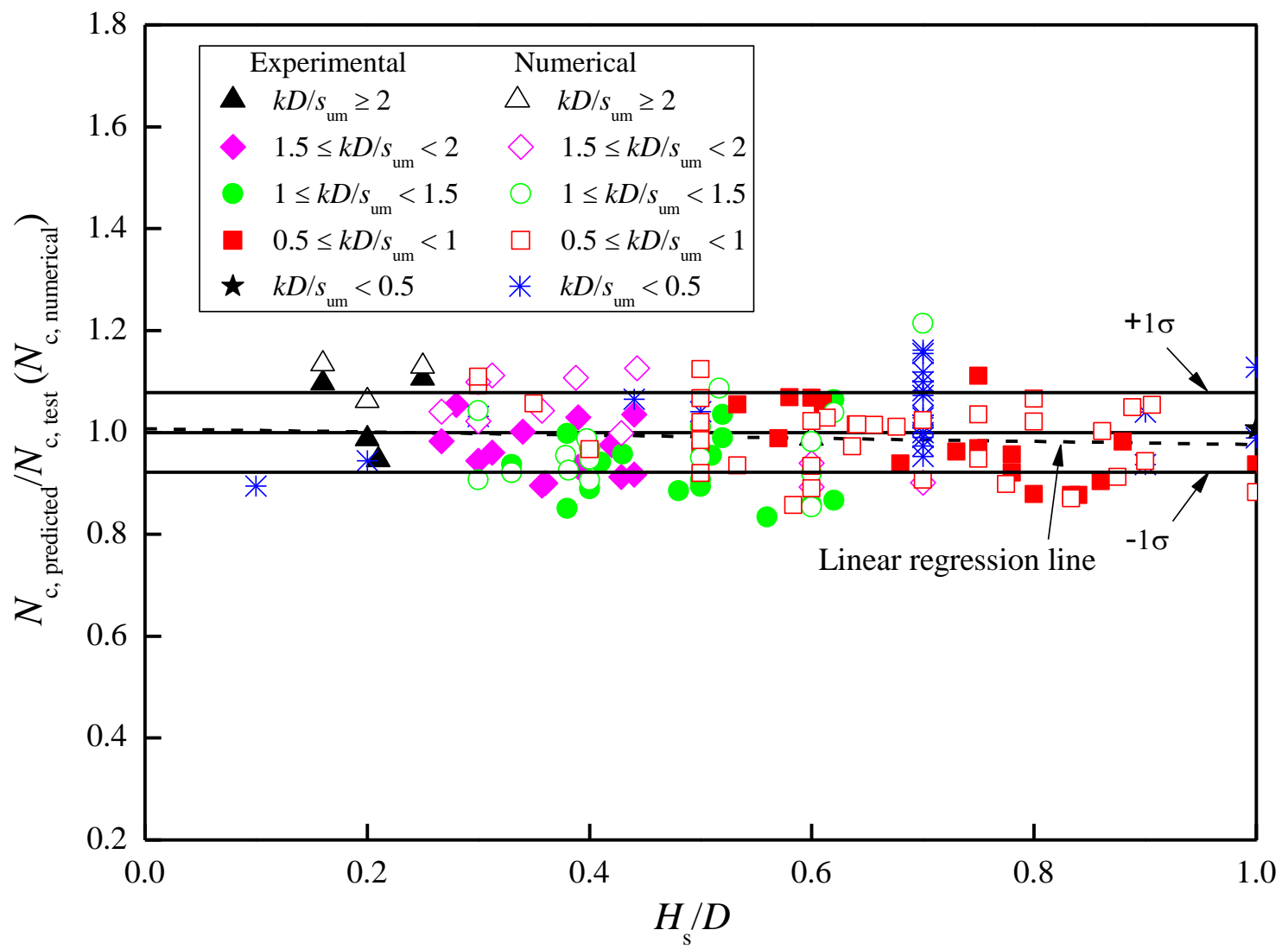

Fig. 13. Verification of the new expression by comparing with the database 


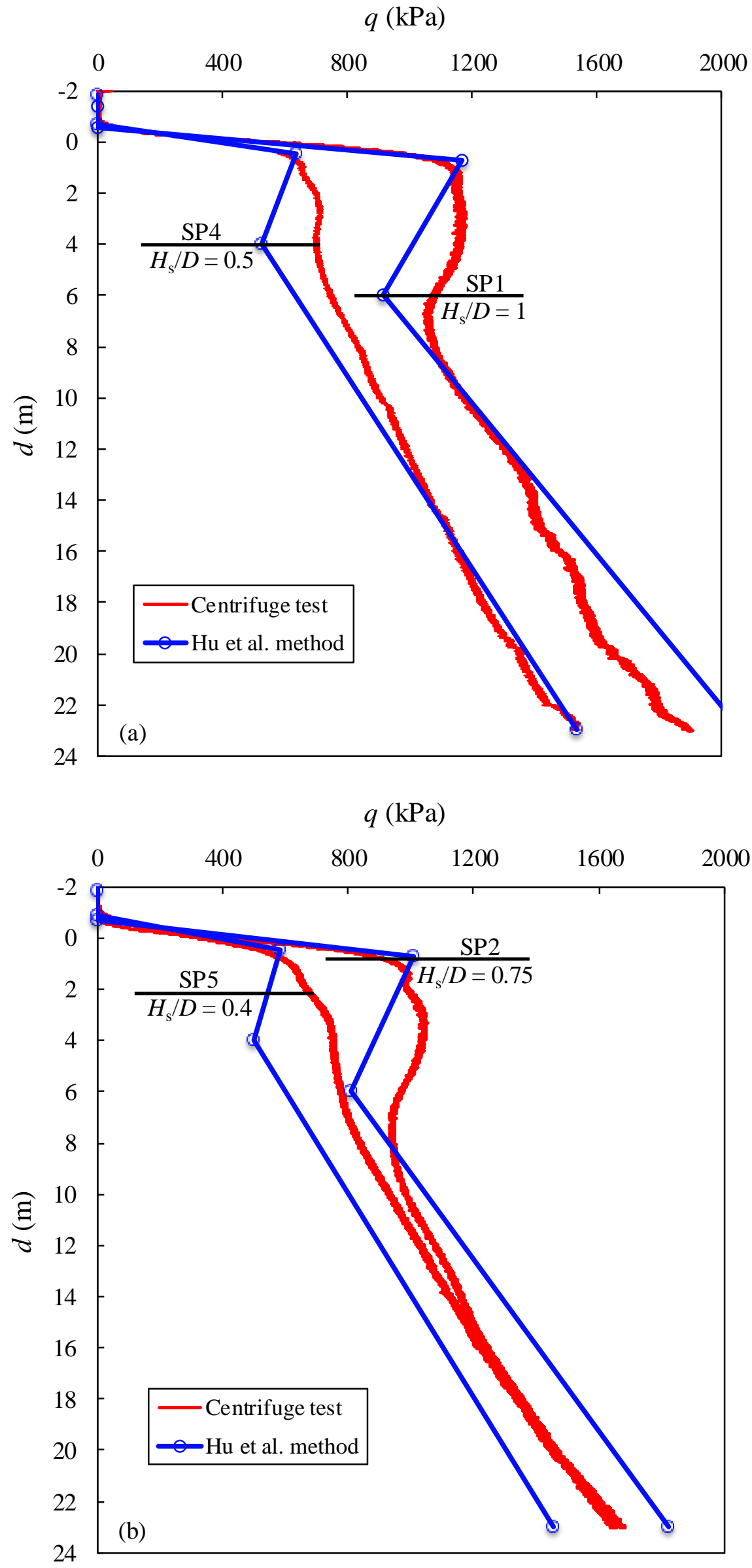




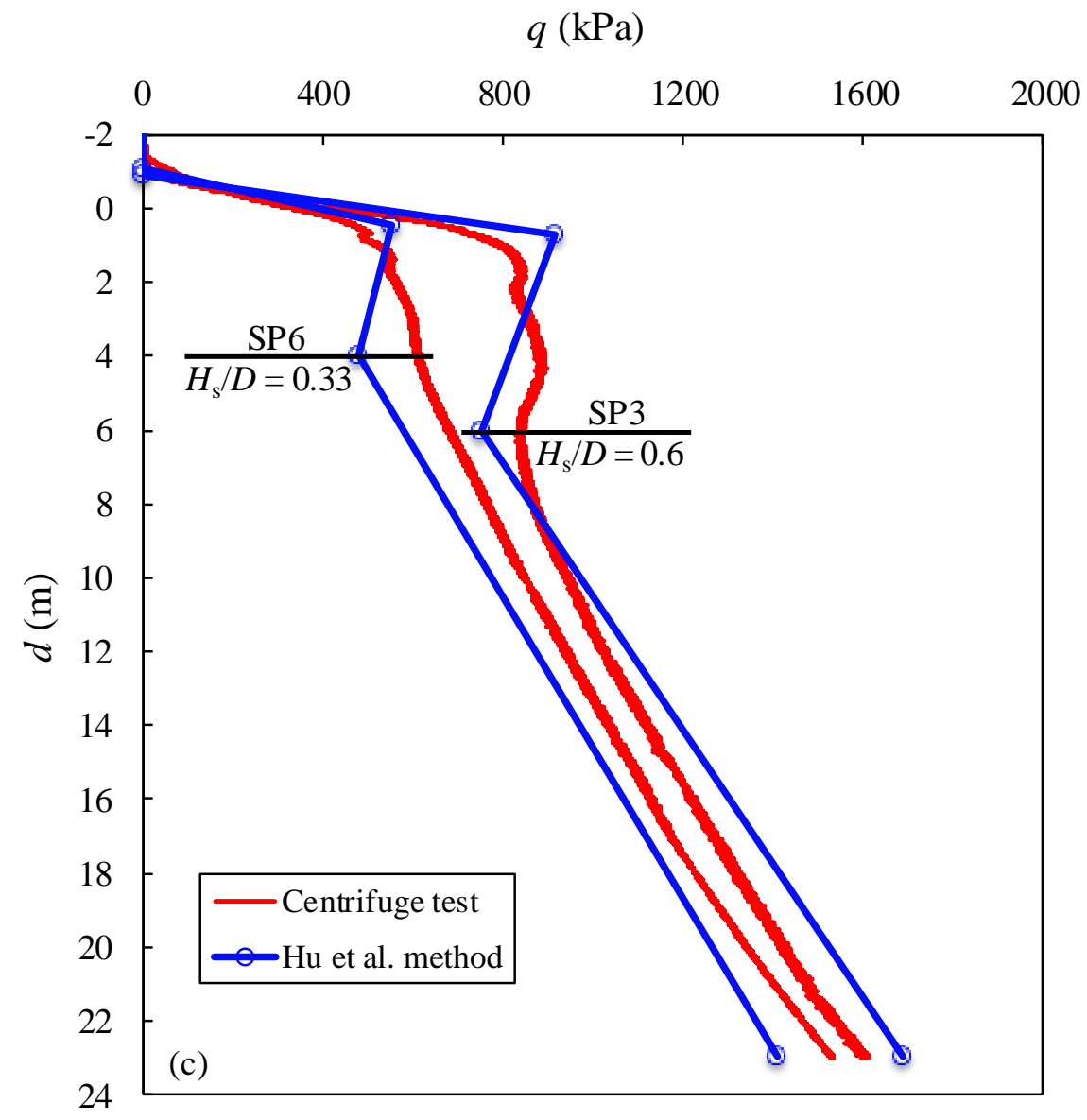

Fig. 14. Experimental and updated predicted spudcan penetration resistance profiles: (a) SP1 and SP4; (b) SP2 and SP5; (c) SP3 and SP6 


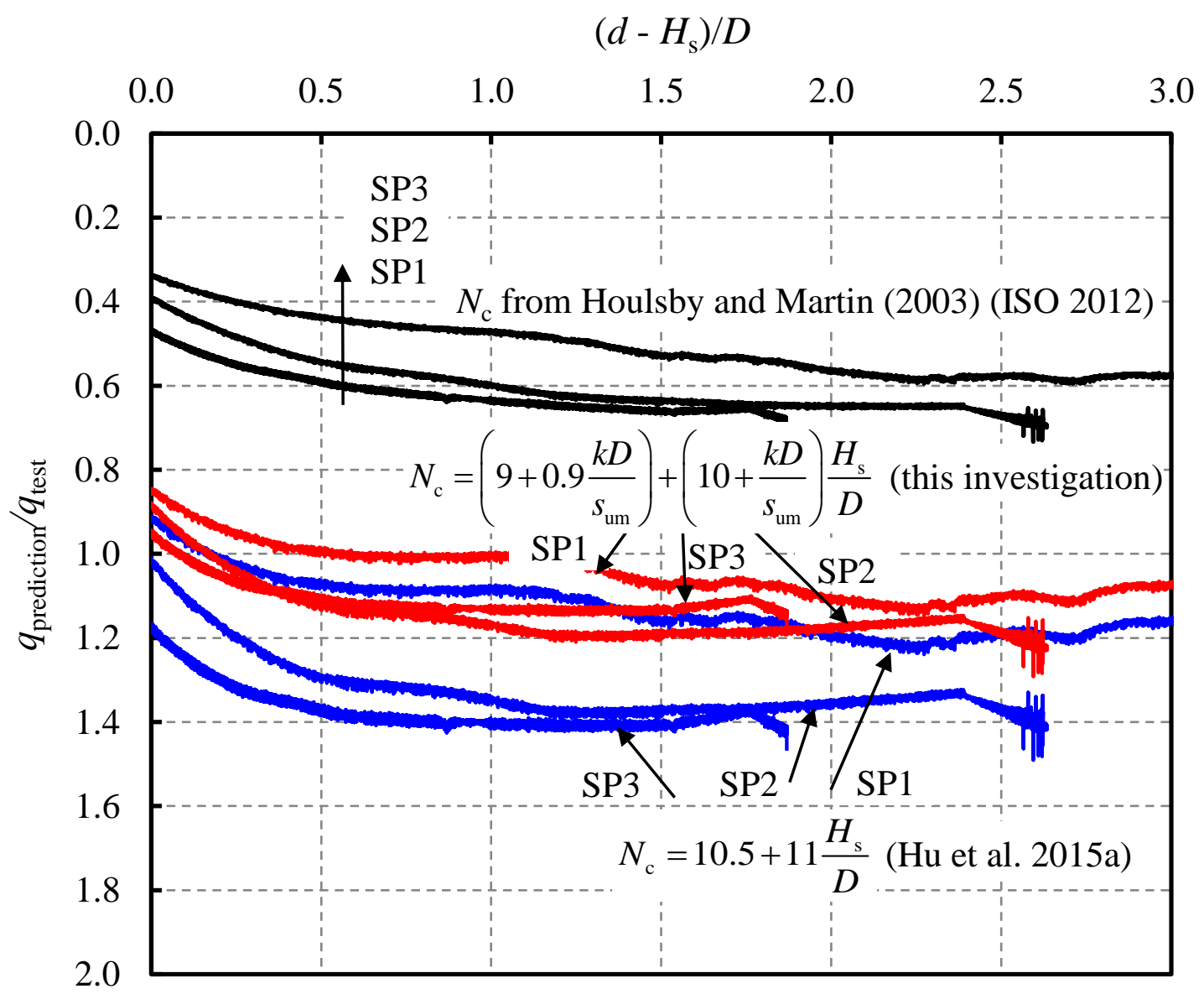

Fig. 15. Performance of the new bearing capacity factor expression 